\title{
Retrieval of atmospheric profiles and cloud properties from IASI spectra using super-channels
}

\author{
X. Liu ${ }^{1}$, D. K. Zhou ${ }^{1}$, A. M. Larar ${ }^{1}$, W. L. Smith ${ }^{2}$, P. Schluessel ${ }^{3}$, S. M. Newman ${ }^{4}$, J. P. Taylor ${ }^{4}$, and W. Wu ${ }^{5}$ \\ ${ }^{1}$ NASA Langley Research Center, Hampton, VA 23681, USA \\ ${ }^{2}$ Hampton University, VA 23668, USA and University of Wisconsin, Madison, WI 53706, USA \\ ${ }^{3}$ EUMETSAT, Am Kavalleriesand 31, 64295 Darmstadt, Germany \\ ${ }^{4}$ Met Office, Exeter, Devon, UK \\ ${ }^{5}$ Science Systems and Applications, Inc., Hampton, VA 23666, USA
}

Received: 23 February 2009 - Published in Atmos. Chem. Phys. Discuss.: 1 April 2009

Revised: 3 November 2009 - Accepted: 8 November 2009 - Published: 3 December 2009

\begin{abstract}
The Infrared Atmospheric Sounding Interferometer (IASI) is an ultra-spectral satellite sensor with $8461 \mathrm{spec}-$ tral channels. IASI spectra contain high information content on atmospheric, cloud, and surface properties. The instrument presents a challenge for using thousands of spectral channels in a physical retrieval system or in a Numerical Weather Prediction (NWP) data assimilation system. In this paper we describe a method of simultaneously retrieving atmospheric temperature, moisture, and cloud properties using all available IASI channels without sacrificing computational speed. The essence of the method is to convert the IASI channel radiance spectra into super-channels by an Empirical Orthogonal Function (EOF) transformation. Studies show that about 100 super-channels are adequate to capture the information content of the radiance spectra. A Principal Component-based Radiative Transfer Model (PCRTM) is used to calculate both the super-channel magnitudes and derivatives with respect to atmospheric profiles and other properties. A physical retrieval algorithm then performs an inversion of atmospheric, cloud, and surface properties in the super channel domain directly therefore both reducing the computational need and preserving the information content of the IASI measurements. While no large-scale validation has been performed on any retrieval methodology presented in this paper, comparisons of the retrieved atmospheric profiles, sea surface temperatures, and surface emissivities with co-located ground- and aircraft-based measurements over four days in Spring 2007 over the South-Central United States indicate excellent agreement.
\end{abstract}

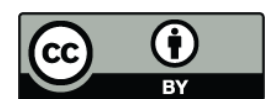

Correspondence to: $\mathrm{X}$. Liu (xu.liu-1@ nasa.gov)

\section{Introduction}

Modern satellite sensors such as Atmospheric Infrared Sounder (AIRS), Infrared Atmospheric Sounding Interferometer (IASI), and Cross-track Infrared Sounder (CrIS) all have two orders of magnitude more spectral channels relative to traditional operational sounders such as the High Resolution Infrared Radiation Sounder (HIRS) and the Geostationary Operational Environmental Satellites (GOES) sounder. These modern sensors represent major advances in the atmospheric sounding capability. Radiance spectra measured by these new sounders can be inverted to provide high resolution atmospheric temperature profiles, humidity profiles, cloud properties, and surface properties. They also provide improved weather and climate observations and forecasting. AIRS is a grating instrument with 2378 spectral channels that was launched on 4 May 2002 aboard of the NASA Earth Observing System (EOS) Aqua satellite. It measures thermal emission from the Earth's atmosphere and the Earth's surface (Chahine et al., 2001; Pagano et al., 2003; Aumann et al., 2003; Goldberg et al., 2003). IASI is an ultra-spectral resolution infrared sounder aboard of the Metop-A satellite and was launched on 19 October 2006. The IASI instrument is a Michelson interferometer with 8461 spectral channels, which measures the top of atmospheric (TOA) infrared radiance (Klaes et al., 2007; Blumstein et al., 2004; Schluessel et al., 2005a). CrIS is the next generation National Polar-orbiting Operational Environmental Satellite System (NPOESS) sounder with 1305 spectral channels and also measures atmospheric and surface emissions (Moncet et al., 2001). The first CrIS instrument will be launched on NASA's NPOESS Preparatory Project (NPP) satellite. The NPOESS and the EUMETSAT Polar System (EPS) will form the Initial

Published by Copernicus Publications on behalf of the European Geosciences Union. 
Joint Polar System capable of providing global soundings with different equator crossing times (Klaes, 2007). Exploring high information content contained in these high spectral resolution spectra is a challenging task due to computational effort involved in modeling thousands of spectral channels. Usually, only very small fractions (4-10 percent) of the available channels are included in a real-time physical retrieval system or a numerical weather prediction (NWP) satellite data assimilation system (Rabier et al., 2002; Collard, 2007; Crevoilier et al., 2003; Prunet et al., 1998; Fourrie and Thepaut, 2002, 2003). For example, the AIRS level 2 physical retrieval algorithms and NWP data assimilation systems use only a few hundred channels for the inversion of atmospheric and surface properties (Chahine, 2001; Suskind et al., 2006, 2003; Le Marshal et al., 2005). Scientists at various satellite data assimilation and NWP centers have shown positive impact on the weather forecast using only a few hundred spectral channels of AIRS data (Le Marshall et al., 2005a, b, 2006). Collard (2007) has selected 300 IASI channels for use in numerical weather predictions applications. Scientists at the European Centre for Medium-range Weather Forecasts (ECMWF) routinely monitor 366 IASI channels and assimilate 168 IASI channels, from which they have shown positive impacts on NWP for both Southern and Northern Hemispheres (Collard and McNally, 2008). The aim of this paper is to demonstrate an efficient way to use all the information from thousands of channels offered by ultra-spectral resolution satellite sounders. We will focus our study on the IASI instrument because it has 8461 channels, which presents a great challenge.

There are several ways to use more channels. One of them is to increase the computational speed of the radiative transfer model needed by the inversion process. There are lots of efforts devoted to the development of fast radiative transfer models for simulating hyper-spectral or ultra-spectral radiances (Strow et al., 2003, 2006; Saunders et al., 2000, 2007; Matricardi, 2003; Matricardi and Saunders, 1999; Moncet et al., 2001; Liu et al., 2003; Edwards et al., 2000; McMillin et al., 1995, 1997; Barnet et al., 2000). These models are orders of magnitude faster than line-by-line radiative transfer models. Because these fast forward models deal with one spectral channel at a time, it is still challenging to incorporate thousands of channel radiances into data assimilation systems. Even if the forward models are fast enough, the Jacobian and channel covariance matrices are so large that it is time consuming to perform matrix operations in an inversion process. Another way to use these thousands of channels is to transform them into some kind of super channels. Because all of these spectral channels are not totally independent of each other, it will be beneficial to explore the correlations between them. By combining channels with similar properties into a super channel, random instrument noises tend to be minimized in this averaging process. McMillin proposed a method for selecting super channels based on the shape of the weighting functions (McMillin, 2004). The resulting super channels span a relative large frequency domain; therefore the fast forward model has to handle the non-linearity of the Planck function carefully. Schluessel (2005b) developed a method for selecting super channels by clustering channels with high correlation coefficients. The super channel is produced by a linear combination of the other channels within that cluster. Aoki $(2004,2005)$ described a method of compressing high resolution infrared spectra into a few hypothetical channels using a regression matrix and EOFs derived from weighting functions. A great compression ratio can be achieved but the forward model has to store a large amount of information at numerous linearization points. The super channel approach we take in this paper is by an EOF transformation of the ultra-spectral radiance spectra. The EOFs are derived from a large ensemble of radiance spectra weighted by the instrument noise. The EOF transformation approach has been used to compress spectra and to improve signal-tonoise ratios (Huang and Antonelli, 2001). One difficulty in using EOF transformed super channels in a retrieval process is that it needs a fast radiative transfer model that does forward modeling in the EOF domain. Liu et al. $(2005,2006)$ have developed a principal component-based radiative transfer model (PCRTM) specifically for hyper and ultra spectral remote sensing applications. The forward model treats the whole spectrum together, therefore removing many redundant calculations that are needed for channel-based radiative transfer models. The PCRTM forward model is capable of producing both the super channel magnitudes and the derivatives of the super channel with respect to retrieved parameters (Jacobian). Therefore there is no need to perform EOF transformations to convert super channels back to spectral space at each iteration step for a variational retrieval or a NWP data assimilation system. In Sect. 2 of this paper, we will describe the basic principles of the PCRTM forward model and how the forward model performs cloud radiative transfer calculations. In Sect. 3, we will describe a physical retrieval algorithm using super channels and the PCRTM forward model. In Sect. 4, we will show some results of applying the PCRTM retrieval system to IASI data observed by the Metop-A satellite. Finally, we will present our summary and conclusions on the super channel retrieval approach.

\section{Forward modeling of super channels under clear and cloudy sky conditions}

\subsection{General description PCRTM forward model}

A super channel is defined as the dot product (or projection coefficient) of a channel radiance spectrum and an EOF or a Principal Component (PC) derived from a large number of hyper or ultra spectral resolution spectra. The EOFs are computed for a wide range of satellite zenith angles ranging from 0 to 66.4 degrees. Because EOFs are orthogonal to each other, they contain highly compressed information content 
of the original radiance spectra. The redundant spectral information (i.e. spectral correlation between channels) is captured via the EOF representation. For an instrument such as IASI with 8461 channels, only about 100 highest-ranking EOFs are needed to regenerate original spectra to an accuracy equivalent to the instrument noise level. The number of super channels is determined by linearly combining various numbers of EOFs and comparing the differences between the regenerated and the original IASI spectra with the instrument noise. Aires et al. (2002) found that for the IASI instrument, an EOF number of 30 for each of the three bands (or 90 total) will give the best compression/de-noising statistics. We have reached a similar conclusion in our studies here and in Liu et al. (2007). These super channels essentially contain all the information content of 8461 IASI channels, while having 84 times less data volume. Unlike traditional fast radiative transfer models, which either predict channel radiances or transmittances, the PCRTM predicts the super channels of the spectrum. The relationship between the super channels and the predictors, i.e. monochromatic radiances, is derived from the properties of eigenvectors and instrument line shape (ILS) functions. Because super channel magnitudes are linear combinations of the channel radiances with eigenvectors as the weights and the eigenvectors are invariant from one spectrum to another, the super channel, $Y_{i}$, is proportional to channel radiance. Therefore it contains the same information content as the original channels spectrum. The channel radiance is calculated via a convolution of the instrument lineshape function (ILS) with monochromatic radiances $\left(R_{k}^{\text {mono }}\right)$ within the frequency span of the ILS:

$R_{i}^{\text {chan }}=\sum_{k=1}^{N} \phi_{k} R_{k}^{\text {mono }}$

where $\phi$ is the normalized ILS. The super channel is linearly related to a set of monochromatic radiances because both eigenvectors and instrument line-shape functions do not vary from one spectrum to another.

$Y_{i}=\sum_{k=1}^{N} a_{k} R_{k}^{\text {mono }}$

Because the monochromatic radiances at various frequencies are highly correlated, only a few hundred of them are needed to accurately predict the super channels. Liu et al. (2005, 2006) have described a method for clustering monochromatic radiances and thereby removing redundant information in the monochromatic radiances. The basic idea is to cluster monochromatic radiances with similar properties together and only select a subset of these monochromatic radiances for generating $Y_{i}$ in Eq. (2). The non-linear relationship between super channels and the atmospheric temperature, $\mathrm{H}_{2} \mathrm{O}$, $\mathrm{O}_{3}, \mathrm{CH}_{4}, \mathrm{~N}_{2} \mathrm{O}$, and $\mathrm{CO}$ profiles, cloud properties, surface properties, and observation geometry is captured via rigorous monochromatic radiative transfer calculations. The super channels are simply linear combinations of these monochromatic radiances, making the PCRTM a physically based radiative transfer model. The coefficients $a_{k}$ are determined by a regression process. Thousands of monochromatic and channel radiance spectra are calculated using a line-by-line radiative transfer code under various atmospheric and surface conditions. Super channels are calculated by projecting the calculated channel spectra onto a set of EOFs. $a_{k}$ are obtained by solving thousands of linear equations according to Eq. (2).

Unlike some of the super channel approaches mentioned in the introduction, the PCRTM radiative transfer model makes it very easy to calculate channel radiances from the super channels. The channel spectrum can be obtained simply by linearly combining the pre-stored eigenvectors with the super channel magnitudes as weights:

$\boldsymbol{R}^{\text {chan }}=\sum_{i=1}^{N_{P C}} Y_{i} \boldsymbol{U}_{i}$

where $N_{p c}$ is the number of significant PCs or EOFs, $\boldsymbol{U}_{i}$ is the $i$-th eigenvector, representing the radiance spectra.

The derivatives of super channels with respect to the state vector (Jacobian) are calculated by calculating the derivatives of monochromatic radiance with respect to state vectors first. Equation (4) is then used to transform the monochromatic derivatives to super channel derivatives. The dimension of the super channel Jacobian matrix is much smaller than that of the channel radiances, an ideal situation for an inversion process.

$\frac{\partial Y_{i}}{\partial X_{j}}=\sum_{k=1}^{N} a_{k} \frac{\partial R_{k}^{\text {mono }}}{\partial X_{j}}$

IASI has a spectral coverage from 645 to $2760 \mathrm{~cm}^{-1}$ with a spectral resolution of $0.5 \mathrm{~cm}^{-1}$ after applying a Gaussian apodisation. The spectral spacing between adjacent channels is $0.25 \mathrm{~cm}^{-1}$. Although the spectral coverage is continuous, an IASI spectrum consists of three spectral bands measured by 3 separate detectors. The first spectral band has 2261 channels and covers spectral range from $645-1210 \mathrm{~cm}^{-1}$, the second band has 3160 channels and covers $1210-2000 \mathrm{~cm}^{-1}$, and the third band has 3040 channels and covers 2000$2760 \mathrm{~cm}^{-1}$. We decided to generate our EOFs separately for each of the IASI bands. The numbers of super channels chosen for each of the three bands are 40, 30, and 30, respectively. As mentioned before, these numbers are determined by projecting IASI spectra onto EOFs and then regenerating the IASI spectra using a various number of PC scores. Our results show that using 100 super channels, we can re-generate IASI spectra with RMS errors less than the instrument noise levels (see the bottom plot in Fig. 3). If we calculate PCs using channels from all three IASI bands together, the number of PCs needed to provide good compression/denoise statistic is also around 100. Choosing separate 


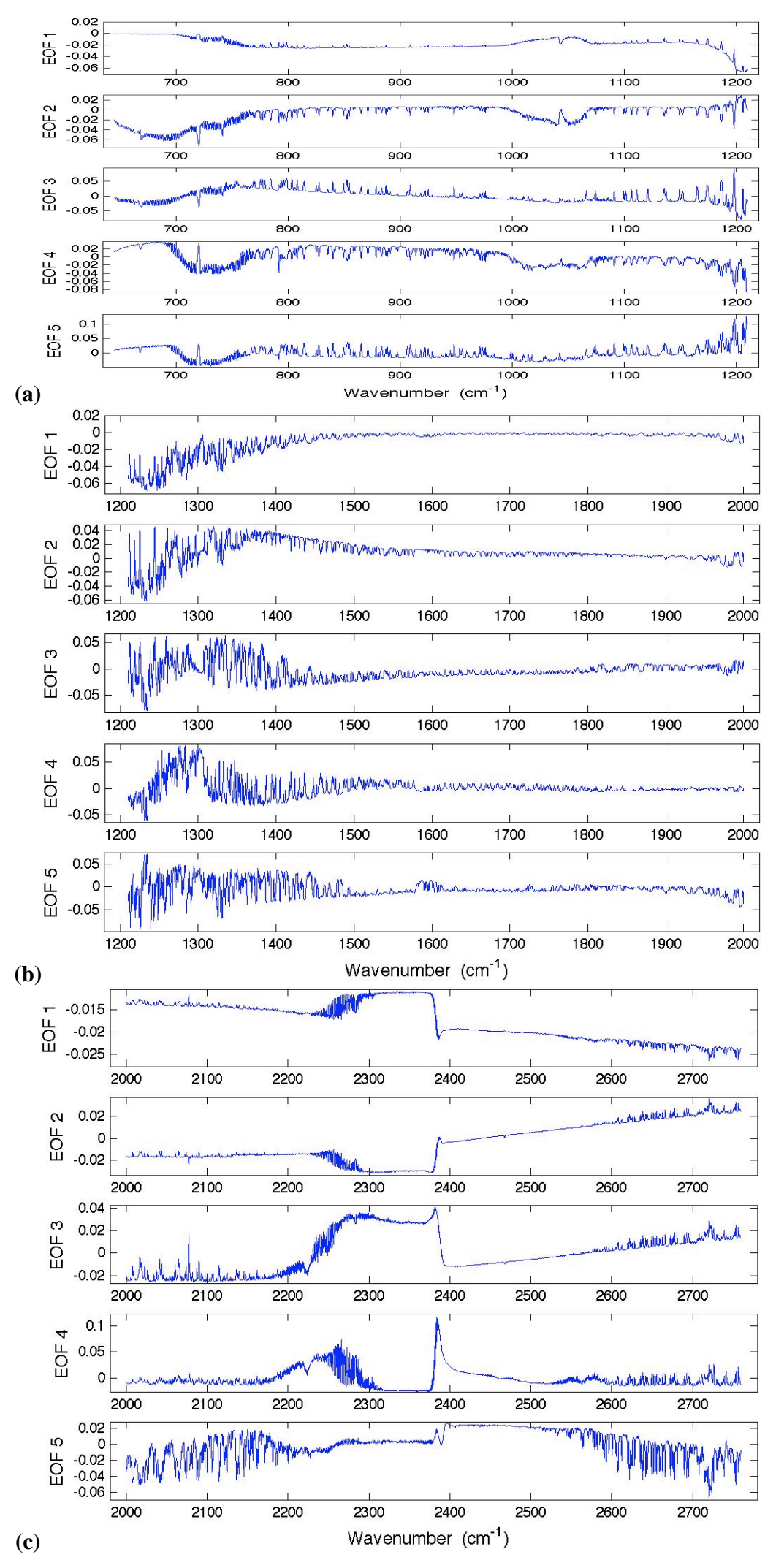

Fig. 1. The first 5 eigenvectors for each of the 3 IASI spectral bands. 

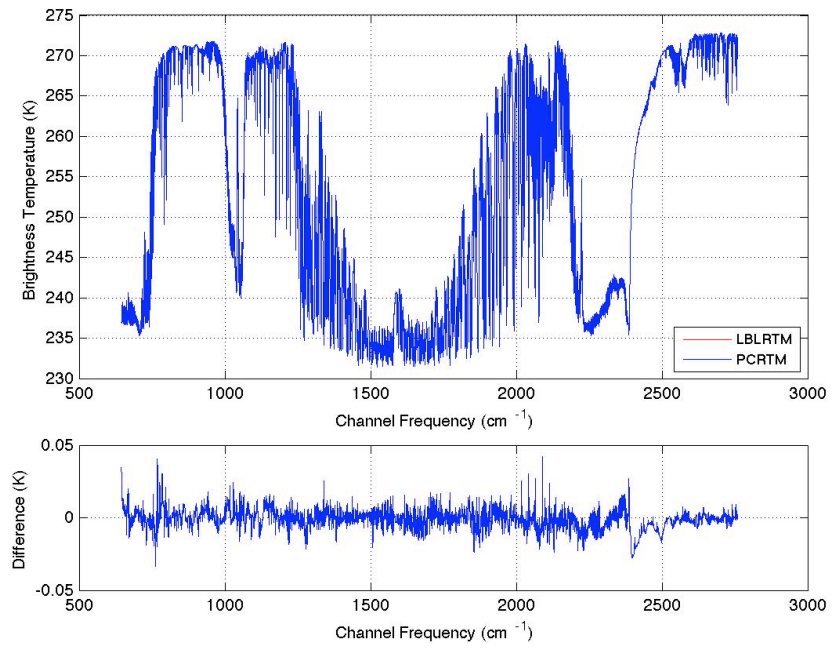

Fig. 2. Top panel: Example of LBLRTM (red line) and PCRTM (blue line) calculated IASI spectra. Bottom panel: Difference between the two spectra shown in top panel.

PCs for each of the IASI bands offers the flexibility of dropping a whole band from the inversion process, e.g. improving computational efficiency when the solar portion of the spectrum is not used in the inversion. Figure 1 shows the first 5 eigenvectors for each of the 3 bands.

The accuracy of the PCRTM forward model has been compared to a Line-By-Line Radiative Transfer Model (LBLRTM, Clough and Iacono 1995), which is the model used for training. Figure 2 shows an example of the IASI radiance spectra calculated by the LBLRTM code and by the PCRTM fast radiative transfer model. The differences between the two spectra are less than $\pm 0.05 \mathrm{~K}$. Figure 3 shows the accuracy of the PCRTM forward model relative to lineby-line radiative transfer model. The RMS errors are typically less than $0.05 \mathrm{~K}$ and bias errors are less than $0.02 \mathrm{~K}$. The bottom panel in Fig. 3 is a plot of the IASI instrument noise in brightness temperature unit at $280 \mathrm{~K}$ scene temperature. The PCRTM errors relative to line-by-line radiative transfer calculations are much smaller than the instrument noise at the respective spectral positions.

The computational efficiency of the forward model depends on many factors such as the way the computer codes are written, the computer platform, and compiler optimizations. We have performed a preliminary comparison of the computational efficiency of the PCRTM model with the channel-based radiative transfer model RTIASI (Matricardi, 2003). The computer platform is a Linux system with a $1.5 \mathrm{GHz}$ Intel Itanium processor and an Intel Fortran compiler. The RTIASI code takes $0.39 \mathrm{~s}$ to calculate 8461 IASI channel radiances. This special version of the RTIASI code does not have a function to calculate the derivatives. It usually takes 2-3 times more computational effort to perform calculations of radiance derivatives relative to atmospheric
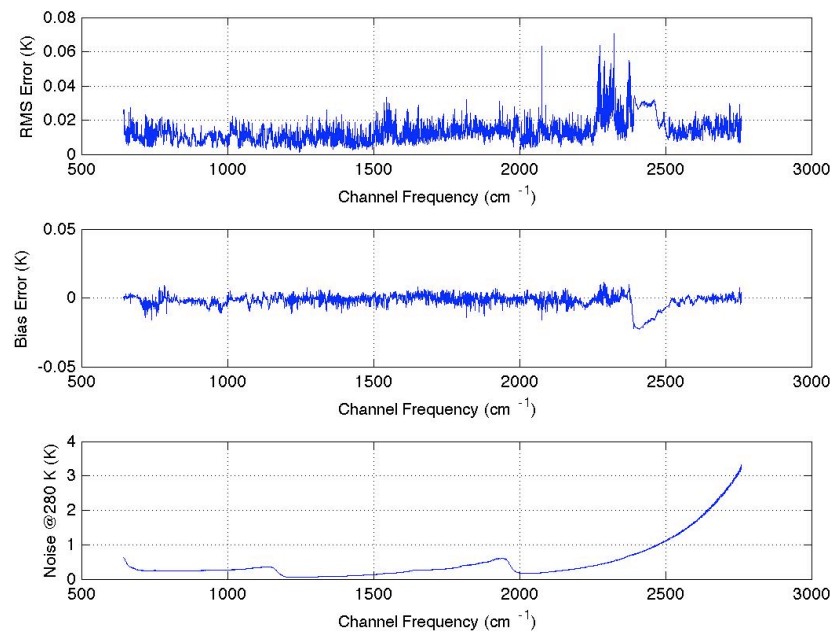

Fig. 3. Top panel: The RMS error between the LBLRTM and PCRTM. Middle panel: The bias errors between the LBLRTM and PCRTM. Bottom panel: The IASI instrument noise at $280 \mathrm{~K}$.
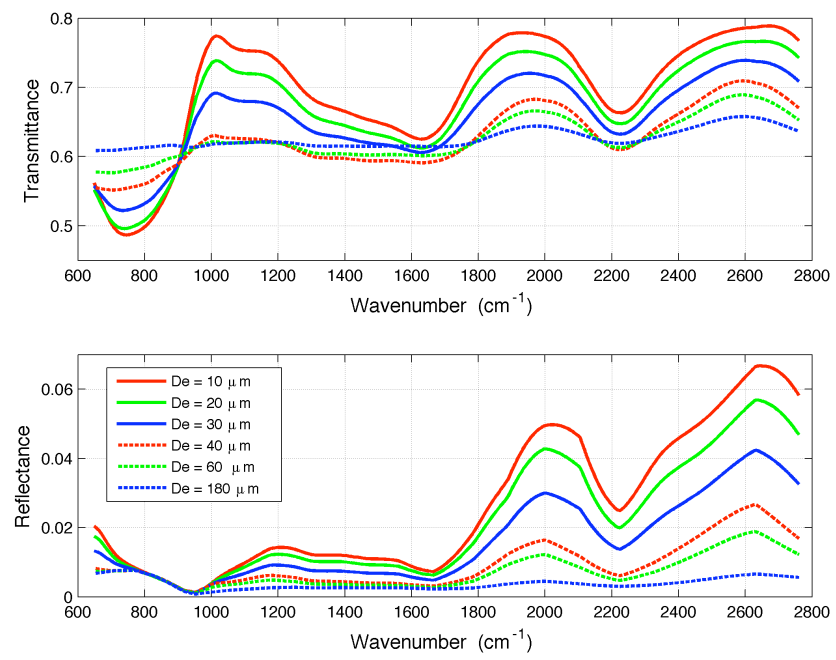

Fig. 4. Cloud reflectance and transmittance for ice clouds at different effective particle sizes.

and surface parameters. The PCRTM takes $0.045 \mathrm{~s}$ to calculate both the 8461 IASI channel radiances and the 100 super channels. It takes $0.038 \mathrm{~s}$ to calculate 100 super channels and associated derivatives. If we perform retrievals using super channels, it should take much less time in the forward model portion of the inversion process. Up to now, we have not made any code optimization with regards to the computational speed of the PCRTM model.

\subsection{Radiative transfer calculation under cloudy conditions}

Based on estimations from data of satellite instruments such as GOES-sounder, HIRS, AIRS, CERES, MODIS and 

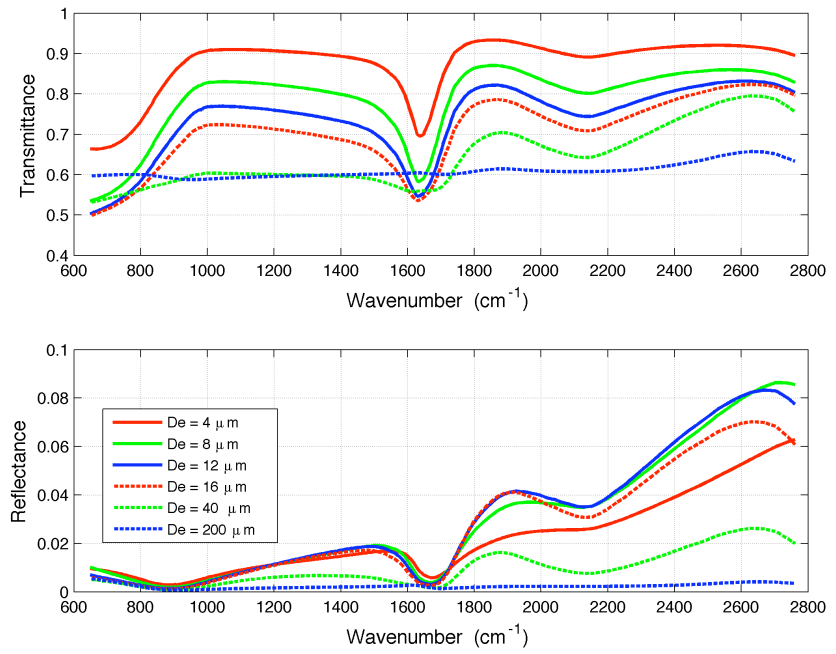

Fig. 5. Cloud reflectance and transmittance for water clouds at different effective particle sizes.

GOES-imager, the likelihood of having no cloud in a pixel with a ground footprint size of 14 to $20 \mathrm{~km}$ is typically less than ten percent globally (Smith et al., 1996). A retrieval algorithm either has to explicitly retrieve cloud properties (Eyre, 1989; Zhou et al., 2005, 2007; Li et al., 2005; Menzel et al., 1983) or remove cloud spectral contributions to the total radiance by using some kind of estimates of clear sky radiances (Suskind et al., 2003, 2006; Chahine, 1974, 1977; Smith, 1968). Some cloud retrieval algorithms such as the $\mathrm{CO}_{2}$-slicing assumes black clouds; therefore ignoring multiple scattering effects of clouds completely. It is highly desirable to have a forward model, which handles the radiative transfer calculations in cloudy atmospheres efficiently. Because PCRTM is a physically based forward model which performs radiative transfer calculations monochromatically, it is easy to incorporate a multiple scattering scheme such as the Discrete Ordinate Radiative Transfer (DISORT) or a adding-doubling (Stammes et al., 1988; Moncet, 1997, Zhang et al., 2007); however such a change will increase computational time and make analytical Jacobian calculations impractical. Here we adopt a method that performs cloud radiative transfer calculations using pre-computed cloud transmittance and reflectance (Yang et al., 2001; Wei et al., 2007; Huang et al., 2006; Niu et al., 2007). By assuming that the cloud scattering is isotropic, one can parameterize cloud scattering properties (effective cloud transmittance and reflectance) as a function of cloud optical depth, cloud particle size, and the satellite zenith angle. The effective reflectances and transmittances have been calculated using DISORT (Stammes et al., 1988) and single scattering properties calculated by Yang et al. (2001), Wei et al. (2007), Huang et al. (2006), Niu et al. (2007). The complex refractive indexes of ice are taken from Warren (1984) with his 1995 update. The complex refractive in- dexes of water are taken from Segelstein (1981). The individual ice cloud particle size distributions are derived from various field campaigns as described by Baum et al. (2007). The single-scattering properties of individual non-spherical ice particles are derived from the composite method (finitedifference time domain method, improved geometric optics method, and Lorenz-Mie theory). A gamma size distribution is assumed for water clouds. Various populations of droxtals, 3-D bullet rosettes, solid columns, plates; hollow columns, and aggregates are assumed in the particle size distributions for the ice clouds (Baum et al., 2007). The cloud optical depth is referenced to a visible wavelength at $550 \mathrm{~nm}$. The infrared cloud optical depth can be related to the visible cloud optical depth according to the following formula:

$\tau(v)=\frac{\overline{Q_{e}(v)}}{\overline{Q_{e}(\mathrm{vis})}} \tau(\mathrm{vis})=\frac{\overline{Q_{e}(v)}}{2} \tau($ vis $)$,

where $\tau$ is the optical thickness at an infrared frequency $v$ or at the visible frequency (vis), $Q_{e}$ is the mean extinction efficiency at a particular frequency. In the visible spectral region near $550 \mathrm{~nm}$, the mean cloud extinction efficiency is assumed to be close to the geometric optics asymptotic value of 2 because the cloud particle sizes are much larger than $550 \mathrm{~nm}$. The effective particle size is defined as the ratio of the volume to the projected area for a given particle size distribution (Niu et al., 2007). For water clouds, the effective particle size is represented by the effective diameter. Figures 4 and 5 show examples of the ice and water cloud reflectance and transmittance calculated in the IASI spectral range for different cloud effective particle sizes. The visible cloud optical depth is fixed at a value of 1.0 and the satellite zenith angle is set to 0.0 for the above calculations. Figures 4 and 5 indicate that the frequency dependencies of ice and water clouds are quite different when particle sizes are small. As the cloud particle size increases, the spectral features become less distinct from each other. The shapes and magnitudes of the cloud transmittance and reflectance can be used to determine cloud phase, cloud optical depth and cloud particle size. In this study, only a single-layer cloud is modeled. The cloud temperature is calculated using the information of cloud top pressure and the atmospheric temperature profile. Because PCRTM calculates monochromatic radiances recursively, adding one cloud layer only adds a slight computational burden. To obtain Top of Atmosphere (TOA) radiance, we start from the surface layer and calculate layer radiation successively. For an atmospheric layer without cloud, the radiance emerging from that layer $\left(R_{l+1, v}\right)$ is calculated according to:

$R_{l+1, v}=R_{l, v} t_{l, v}+\left(1-t_{l, v}\right) B\left(T_{l}, v\right)$,

where $R_{l, v}$ is the radiation below the atmospheric layer $l$ at frequency $v$. The term $t_{l, v}$ is the layer transmittance. $B$ is the Planck function calculated at frequency $v$ for a given layer temperature $T_{l}$. When a cloud layer is reached, the radiance emerging from the top of the cloud layer is given by:

$R_{l+1, v}=R_{l, v} t_{l, v}+\left(1-t_{\text {cloud, } \mathrm{v}}-r_{\text {cloud,v }}\right) B\left(T_{\text {cloud }}, v\right)$ 

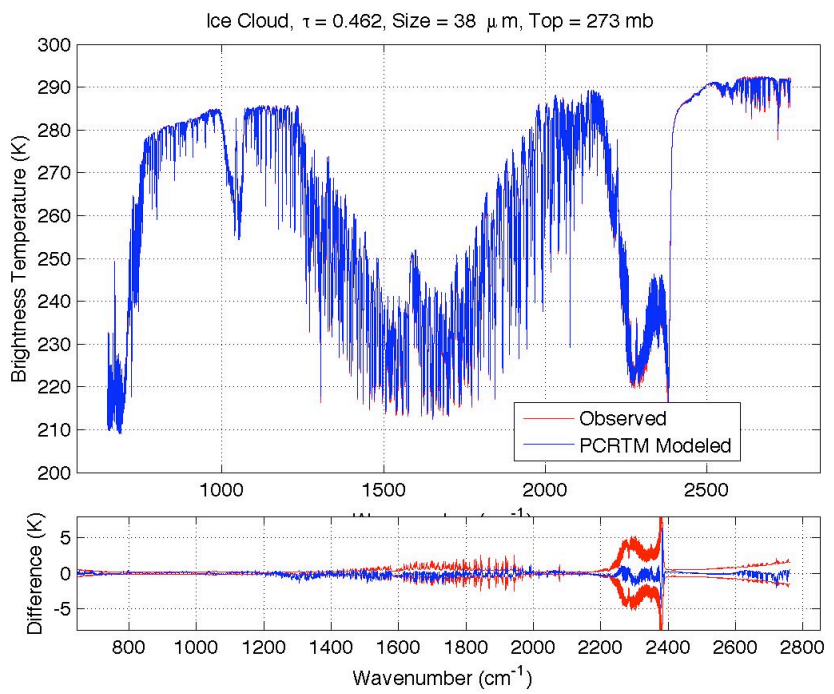

Fig. 6. Top: Observed IASI cloudy spectrum and the PCRTM modeled ice cloud spectrum. Bottom panel: Difference between observed and calculated IASI spectra (blue curve) and the IASI instrument noise converted to brightness temperature unit (red curves).

$$
+r_{\text {cloud, }} R_{\text {down }}
$$

where $t_{\text {cloud,v }}$ and $r_{\text {cloud,v }}$ are the cloud transmittance and reflectance, respectively. $T_{\text {cloud }}$ is the cloud temperature, and $R_{\text {down }}$ is the downwelling radiance at the cloud top. The whole radiative transfer calculation is very similar to a clear sky TOA radiance calculation, making the PCRTM very fast when dealing with clouds.

Instead of showing simulated TOA radiance spectra which contain ice and water clouds, we will show two examples of cloudy radiance spectra observed by the IASI instrument on 15 April 2008 over Angra Dos Reis, Brazil. In addition, we will show how well the PCRTM with the cloud model described above can fit the spectra to a very good accuracy for these cases. The top panel in Fig. 6 contains two IASI brightness temperature spectra, one observed by the IASI and the other calculated using cloud parameters retrieved by the physical retrieval algorithm discussed in this paper. The retrieval algorithm identifies the cloud phase as ice. The retrieved cloud top pressure is at $273 \mathrm{hPa}$. The cloud effective size is $38 \mu \mathrm{m}$ and the cloud visible optical depth is 0.462 . The bottom panel of the figure shows the difference between the observed and the calculated IASI spectra. They agree with each other within the IASI instrument noise levels (shown in red lines) in most of the spectral regions. In the spectral range from 1200 to $1550 \mathrm{~cm}^{-1}$, the IASI instrument has excellent noise performance, we had to relax the weightings for channels in this spectral region to account for errors such as forward model (relative to real observation, not relative to LBLRTM) and not knowing the atmospheric concentrations of $\mathrm{CH}_{4}, \mathrm{~N}_{2} \mathrm{O}$, and other trace gases. Figure 7 shows another case of IASI observed and calculated spectra con-
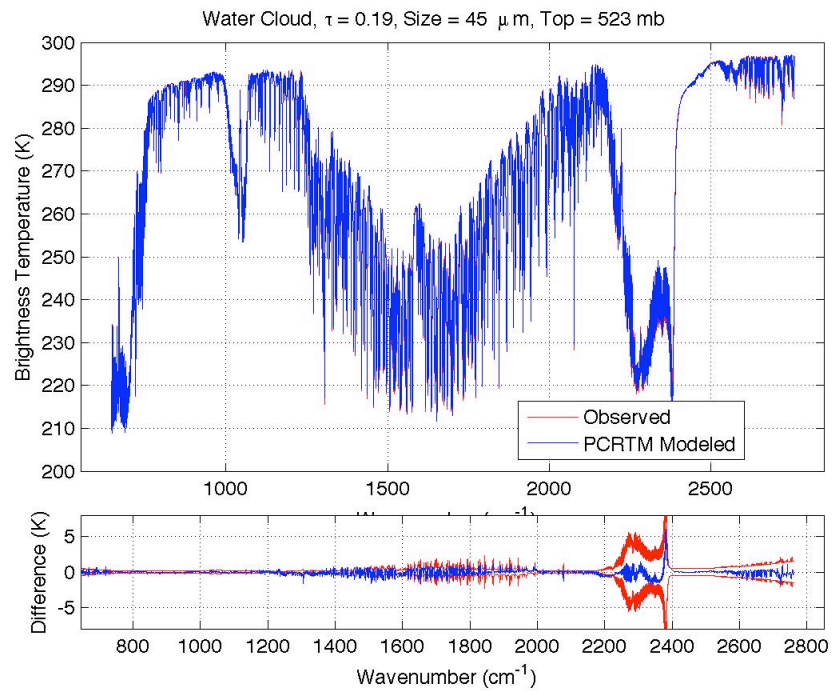

Fig. 7. Top: Observed IASI cloudy spectrum and the PCRTM modeled water cloud spectrum. Bottom panel: Difference between observed and calculated IASI spectra (blue curve) and the IASI instrument noise converted to brightness temperature unit (red curves).

taining water clouds. The retrieval algorithm identifies the cloud phase as water, and the retrieved cloud top pressure is $523 \mathrm{hPa}$, which is located at much lower altitude relative to the ice clouds shown in Fig. 6. The effective cloud particle diameter is $45 \mu \mathrm{m}$ and the cloud visible optical depth is 0.19 . Again, the bottom panel of the figure shows the differences between the observed and the calculated IASI spectra, which are smaller than instrument random noise in most of the spectral regions. The $45 \mu \mathrm{m}$ effective diameter seems to be too large for water clouds. This could be caused by crosstalk between the cloud parameters and other parameters, such as surface emissivity, during the retrieval process. It is also possible that the algorithm incorrectly identifies the ice cloud as water cloud giving large cloud size. As seen from Figs. 4 and 5 , for similar cloud particle size, the ice cloud has a larger slope in the spectral region from 800 to $1000 \mathrm{~cm}^{-1}$. The $40 \mu \mathrm{m}$ water cloud has similar effective transmittance and reflectance as the $60 \mu \mathrm{m}$ ice cloud. Validation of retrieved cloud parameter products is an ongoing effort and, with the availability of coincident truth data, will be the subject of studies to be reported on in the future. Even prior to validation of our cloud parameters, cloud-detection stand-alone is valuable for interpretation of our confident thermodynamic retrievals. 

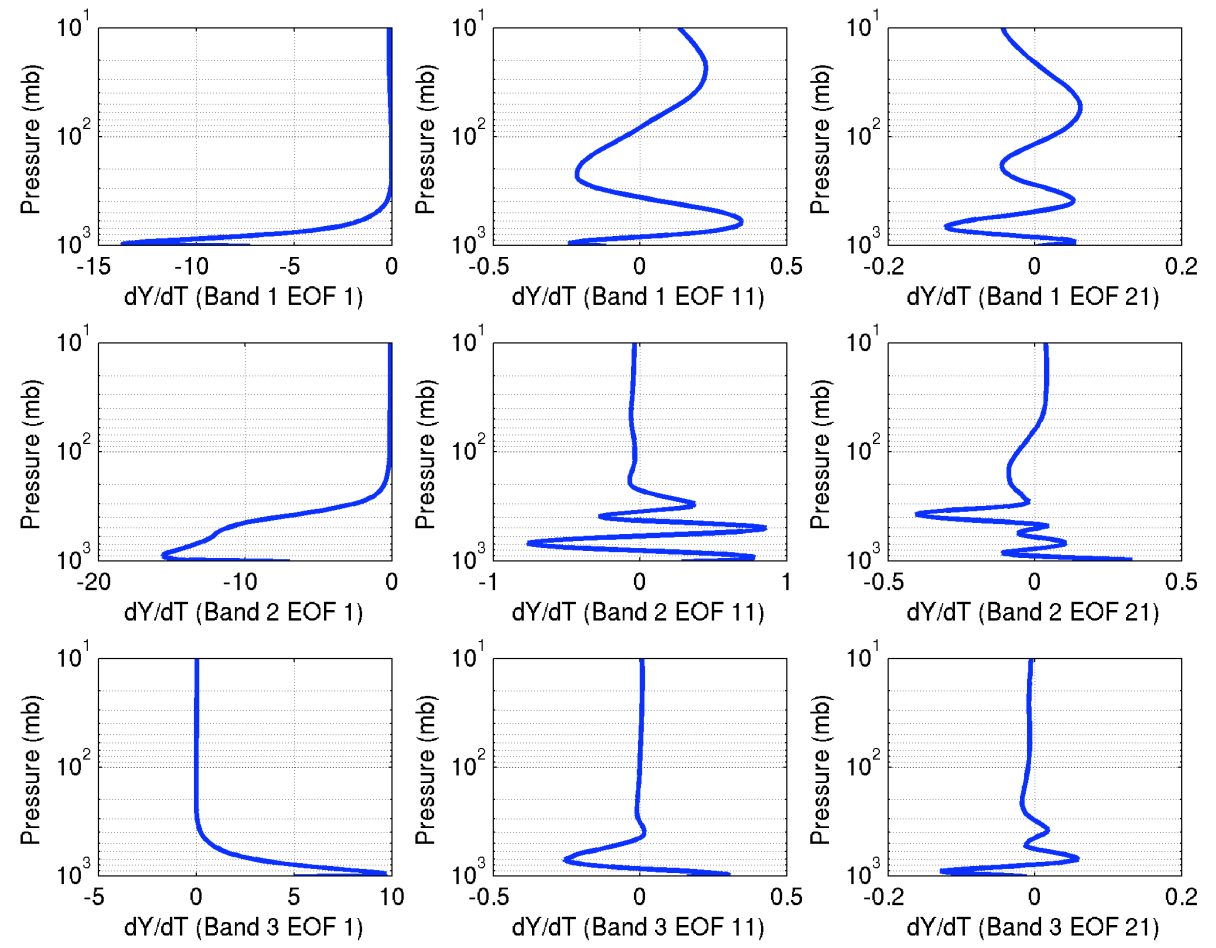

Fig. 8. Temperature weighting functions of the first, the 11th, and the 21 st super channels with respect to atmospheric temperature for each of the three IASI spectral bands.

\section{Description of a super channel based retrieval algorithm}

The objective of an inversion algorithm is to retrieve a state vector. We define our state vector as atmospheric temperature vertical profile, moisture and trace gas vertical profiles, cloud properties, surface skin temperature, and surface emissivities. As mentioned in the previous section, the super channels contain all the information of the original channel spectrum but with a much smaller dimension. Using super channels has an advantage over selecting a small fraction of radiance channels in reducing random instrument noises. By inverting the super channels directly, we retain all the information with regard to the state vector while saving computational time.

Figure 8 shows three weighting functions of the first, the 11 th, and the 21st super channels with respect to atmospheric temperature for each of the three IASI spectral bands. The first eigenvector contains information of broad atmospheric features, especially the temperature information near the Earth's surface. It also has the highest signal-to-noise ratio. In general, the weighting function magnitudes decrease while the vertical structures increase for those super channels that correspond to higher order eigenvectors with finer spectral signatures. It is noted that some of the super-channel weighting functions appear to be correlated between different atmospheric levels, indicating that one eigenvector may contain temperature information for several atmospheric levels. By performing an EOF transformation, these weighting functions can be easily converted to channel-based weighting functions.

Because the weighting functions with fine atmospheric vertical structures have smaller signal-to-noise ratios as compared to those with large structures (see example Figs. 8 and 9), it is difficult to find a unique solution for the inversion process. Many solutions with different fine vertical structures (such as oscillatory profiles) can satisfy the radiative transfer equation and produce super channels or spectral radiances that agree with the IASI observations to within noise level. Therefore, the inversion of atmospheric profiles is an inherently ill-posed problem. From the radiative transfer modeling point of view, we need numerous atmospheric layers in order to accurately represent thermal emissions from the inhomogeneous atmosphere. From the retrieval point of view, having too many layers may produce a degenerate Jacobian matrix (e.g. two layers with same weighting functions) that in turn will cause the instability in the inversion process. We try to regularize the solution two fold. We first transform atmospheric temperature, moisture, ozone, and CO profiles from a 101 vertical level pressure grid to a much smaller dimension by EOF transformation. We then use maximum-likelihood methods with a climatology covariance matrix to constrain our solution. Table 1 shows the original pressure grid for various components of the state vector and the dimensions 

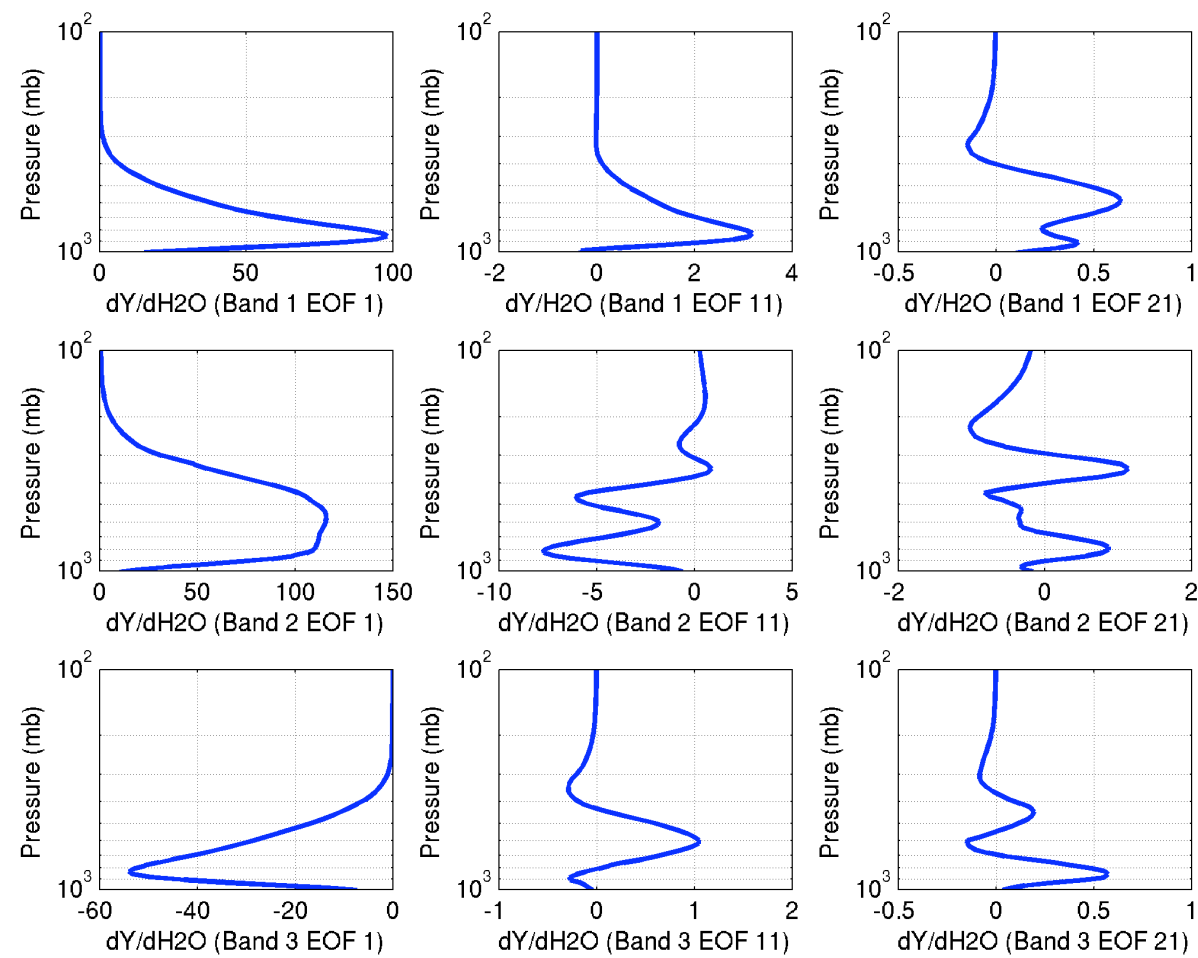

Fig. 9. Logarithm of the atmospheric moisture weighting functions of the first, the 11th, and the 21 st super channels with respect to atmospheric temperature for each of the three IASI spectral bands.

Table 1. Comparison of state vector dimensions before and after EOF compression.

\begin{tabular}{lcc}
\hline State vector & Pressure or frequency grid & Number of EOF used \\
\hline Atmospheric temperature profile & 101 & 25 \\
Atmospheric moisture profile & 101 & 20 \\
Atmospheric ozone profile & 101 & 15 \\
Atmospheric CO profile & 101 & 3 \\
\hline
\end{tabular}

after the EOF compression. The atmospheric temperature and moisture profile EOFs were generated from global radiosonde databases and ECMWF profiles. The ozone profiles EOFs are generated from ozone radio-soundings and satellite measurements. The $\mathrm{CO}$ profile EOFs are generated from the NCAR Mozart model (Kinnison et al., 2007).

For the surface emissivity retrieval, we compress the surface emissivity into PC scores as well (Zhou et al., 2007; Liu et al., 2007). Since the spectral features of the surface emissivity are broad, there is no need to retrieve them at each channel frequency. The surface emissivity EOFs were generated from an ensemble of surface emissivities calculated using an ocean emissivity model (Musuda, 1988; Wu and Smith, 1997) and selected from the Salisbury emissivity library (Salisbury et al., 1992). In addition to atmospheric temperature, moisture, ozone and carbon monoxide vertical profiles, surface skin temperature and surface emissivity; cloud optical depth, cloud particle size and cloud height are also retrieved. The retrieval methodology for cloud parameter retrieval has been discussed in our previous papers (Zhou et al., $2005,2007,2009)$. The cloud phase is determined from the retrieved cloud height and temperature profile (Zhou et al., 2005, 2007).

Because super channels are non-linearly related to the state vector, an iterative approach is needed to solve the non-linear equation. A Levenberg-Marquardt method (Marquardt, 1963; Press et al., 1992) is used to deal with the nonlinearity in the maximum-likelihood inversion:

$$
\begin{aligned}
X_{n+1}-x_{a}= & \left(K^{T} S_{y}^{-1} K+\lambda D+S_{a}^{-1}\right)^{-1} K^{T} S_{y}^{-1}\left[\left(y_{m}-y_{n}\right)\right. \\
& \left.+K\left(x_{n}-x_{a}\right)\right],
\end{aligned}
$$

where the subscripts $n$ and $a$ represent iteration number and a priori, respectively. $y_{m}$ is the super channels of the measured radiance spectrum. $y_{n}$ is the forward model calculated 

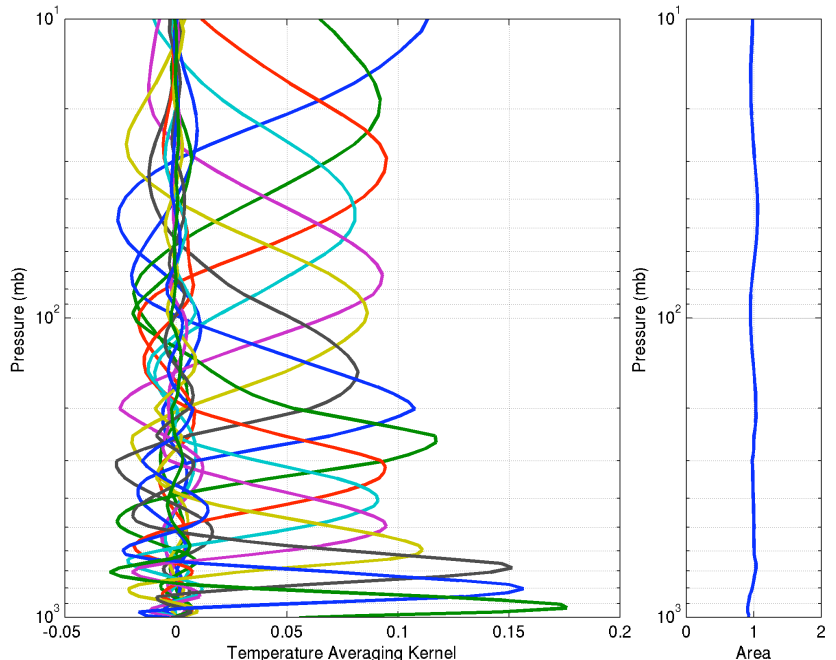

Fig. 10. Left: Averaging kernel for atmospheric temperature profiles at selected pressure levels. Right: The integrated area of the temperature-averaging kernel at each atmospheric pressure level.

super channels using the state vector obtained from the $n$-th iteration. $S_{y}$ and $S_{a}$ are error covariance matrices associated with $y$ and background state vector $x_{a}$, respectively. $x_{0}$ is the first guess used in the retrieval process. $D$ is a diagonal matrix whose elements are determined by the diagonal elements of the $K^{T} S_{y}^{-1} K$ matrix. $\lambda$ is the Lagrange multiplier whose value is adjusted according to the values of the cost function during the iteration process. $S_{y}$ is obtained by EOF transformation of the IASI instrument noise covariance matrix $\left(S_{\text {Rad }}\right)$ :

$S_{y}=\mathbf{U}^{T} \cdot S_{\mathrm{Rad}} \cdot U$.

$\mathbf{U}$ is a matrix that contains the radiance eigenvectors.

The cost function is defined as:

$C=\left(y_{n}-y_{m}\right) S_{y}^{-1}\left(y_{n}-y_{m}\right)+\left(x_{n}-x_{a}\right) S_{a}^{-1}\left(x_{n}-x_{a}\right)$.

We can start the iteration with an $x_{0}$ either equal to the climatology background $x_{a}$ or a first guess which comes from a regression retrieval. The details of the EOF regression retrieval has been discribed by Zhou et al. (2005). The starting value of $\lambda$ is selected based on how close the initial guess of the state vector is to the final solution. If the initial guess of the state vector is from a regression retrieval, the starting value of the $\lambda$ is on the order of 0.01 . If the initial guess is from climatology, the starting value of the $\lambda$ is set to a larger number (e.g. 0.5). During the iteration process, if the cost function decreases, a new forward model calculation will be done using the updated state vector. The value of the $\lambda$ will be decreased by a factor of 5 . If the cost function increases, the value of $\lambda$ will be increased and no forward model calculation will be done for the next iteration. The iteration will stop if any of the following three conditions are satisfied: (1) relative change in cost function is less than 5 percent,
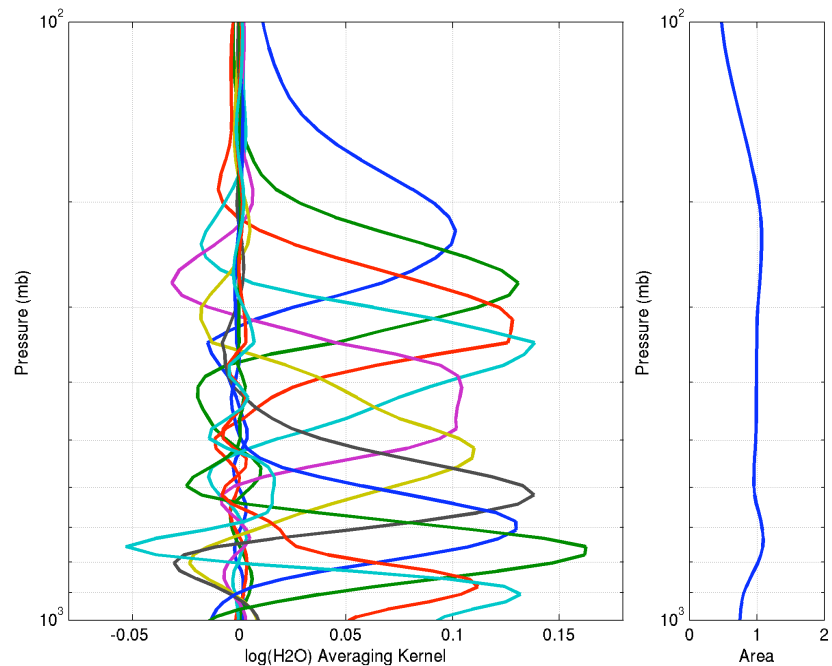

Fig. 11. Left: Averaging kernel for atmospheric moisture profiles at selected pressure levels. Right: The integrated area of the temperature-averaging kernel at each atmospheric pressure level.

(2) relative change in the state vector is less the 5 percent, and (3) maximum number of iterations exceeds 6 . The value of the cost function at the last iteration can be used for control of the retrieved product. In theory, the cost function should be close to the number of super channels used in the retrieval (e.g. 100). If the cost function is too large (e.g. 500), the retrieval is considered not converged. This large cost function could be caused by bad IASI spectra, complex cloudy scenes, or inhomogeneous surface conditions within the IASI field of view. We can output the EOF compressed state vector, PCRTM calculated super channel magnitude, and error covariance matrix associated with the retrieval. The dimension of the retrieval error covariance matrix is small because we compress state vectors into EOF space. The retrieval error covariance matrix is defined as:

$S_{x}=\left(K^{T} \cdot S_{y}^{-1} \cdot K+S_{a}^{-1}\right)^{-1}$.

Having smaller dimensions for various matrices is an implicit advantage of the PCRTM retrieval algorithm. The retrieved state vector is converted into a normal pressure grid or frequency grid via EOF transformations to obtain atmospheric profiles or surface emissivities. If radiance spectra are desired, a radiance-based EOF transformation of the PCRTM calculated super channel vector would be performed. The inversion computational efficiency depends on the size of the $\mathbf{K}$ matrix and how fast a forward model can calculate the $\boldsymbol{y}$ vector. Since we only need 100 super channels (as compared to 200-8461 channels for the standard channel-based method), the $\mathbf{K}$ matrix is much smaller in our case. Therefore the inversion portion of the retrieval system should be faster relative to using all IASI spectral channels. 


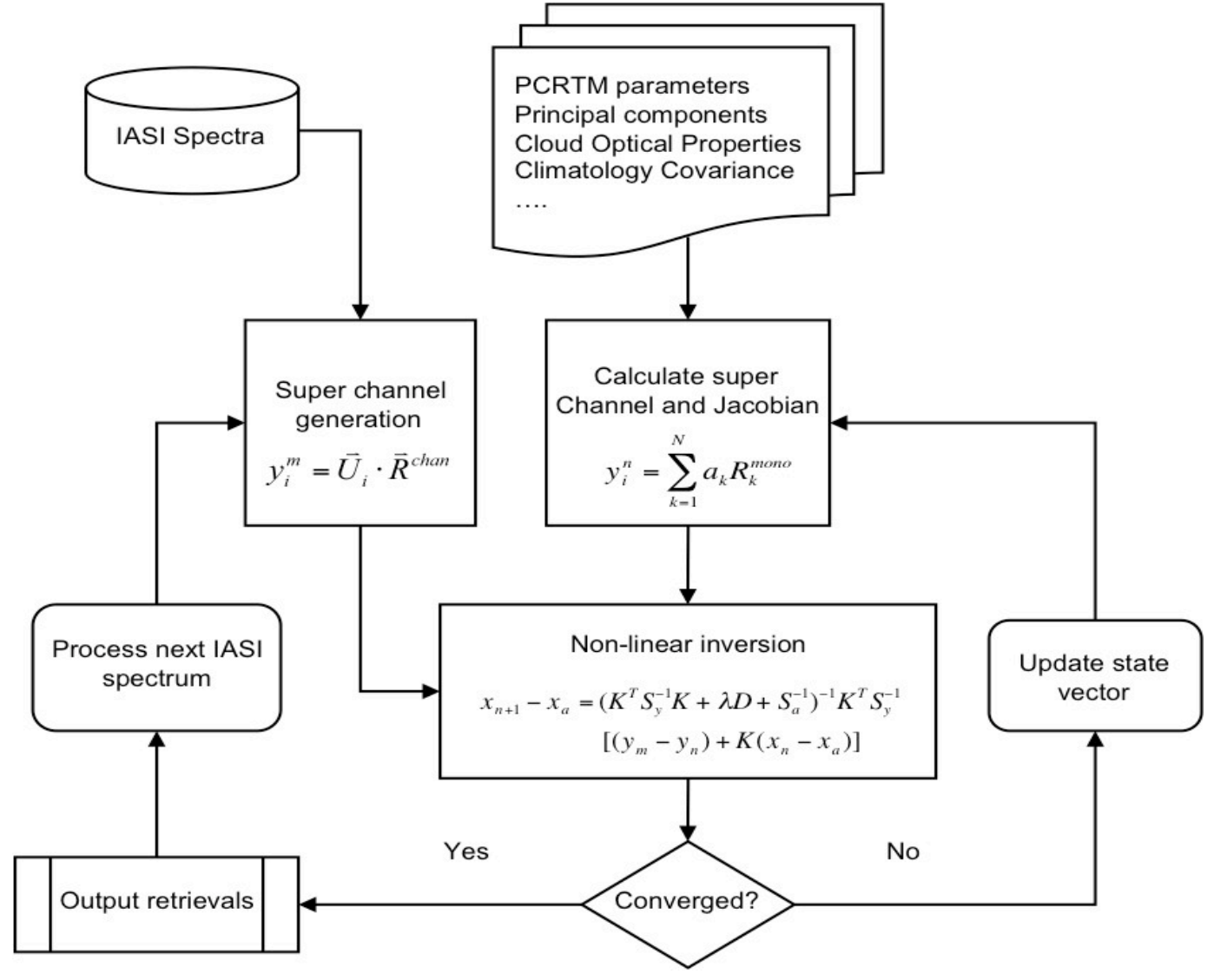

Fig. 12. Flow diagram of the PCRTM IASI retrieval process.

To characterize the vertical resolution of the retrieved atmospheric temperature and moisture profiles, the averaging kernel can be calculated (Rodgers, 1976, 2002):

$A V_{x}=\left(K^{T} \cdot S_{y}^{-1} \cdot K+S_{a}^{-1}\right)^{-1} K^{T} \cdot S_{y}^{-1} \cdot K$.

Again, the dimension of the averaging kernel is small. Most of the quantities needed for the averaging kernel calculation are already calculated during the physical inversion process.

Figures 10 and 11 are examples of typical averaging kernels for atmospheric temperature and moisture, and only selected levels are shown for clarity. The peaks of the averaging kernels correspond well with the pressure levels where the atmospheric profiles are perturbed relative to the truth. The integrated area of the averaging kernel should give a good indication where the information is coming from. For those levels with the area values close to 1.0 , one hundred percent of the information comes from the measurement, i.e. observed IASI spectrum. For a level with the integrated area value of $\alpha$ (where $\alpha$ is a number less than 1 and greater than 0 ), only a fraction $\alpha$ of the information is from the measurement. The remaining fraction of information is from a priori. It is clear from Fig. 10 that the retrieved temperature information at almost all the altitudes is basically from IASI measurements. Only 10 percent of the information is from the a priori for the near-surface altitudes. It should be mentioned that the shape, the resolution, and the area of the averaging kernel depend on many of factors such as the structure of the atmospheric profiles, the thermal contrast between air temperature and the surface skin temperature, and the instrument noises. For some other profiles, the retrieved air temperature near the Earth's surface could be solely determined from the IASI spectrum without contribution from a priori information. The half-width of the averaging kernel is a very good measure of the vertical resolution of the retrieval system. Figures 10 and 11 show that the retrieval system has a better vertical resolution for the atmospheric temperature than the atmospheric moisture. As the altitude increases, the vertical resolution for temperature decreases. Figure 11 does not include moisture averaging kernels above $200 \mathrm{hPa}$. The high altitude $\mathrm{H}_{2} \mathrm{O}$ averaging kernels seem to peak at lower altitudes as they should be. For high altitudes above $200 \mathrm{hPa}$, about 5 to 50 percent of the information is from a priori, as indicated by the integrated area of the $\mathrm{H}_{2} \mathrm{O}$ averaging kernels. This result could be caused by the fact that the climatology covariance matrix for $\mathrm{H}_{2} \mathrm{O}$ above $300 \mathrm{hPa}$ is not realistic because the statistics of moisture profiles from radiosondes measurements are not good. It is well known that radiosondes either have no values or have poor quality measurements 

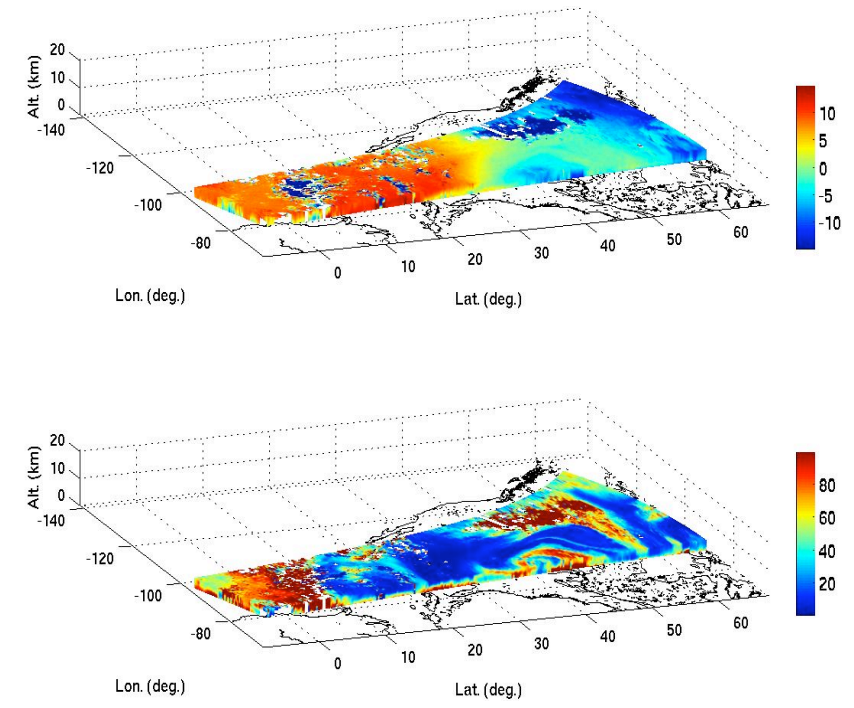

Fig. 13. Cross sections of the temperature in unit of Kelvin (top) and relative humidity in unit of percent (bottom) retrieved from IASI spectra taken on 19 April 2007 (see text).

above $300 \mathrm{hPa} . \mathrm{H}_{2} \mathrm{O}$ values above $300 \mathrm{hPa}$ are sometimes generated by a regression from the lower altitudes or by a simple extrapolation. Therefore the $\mathrm{H}_{2} \mathrm{O}$ covariance matrix above $300 \mathrm{hPa}$ is highly correlated and the retrieval system may overly constrain the solution towards the a priori. The integrated areas of the $\mathrm{H}_{2} \mathrm{O}$ averaging kernel are close to 1 for an altitude range from $200 \mathrm{hPa}$ to $800 \mathrm{hPa}$, indicating that the retrieval has good sensitivity in this altitude range. It should be emphasized that even though the weighting functions shown in Figs. 8 and 9 are not localized to a particular altitude and appear to be correlated between different levels, the retrieval system does provide nicely peaked averaging kernels. The result confirms that the EOF transformation of the radiance spectrum into super channels preserves the information content of the IASI instrument.

\section{Retrieval results from METOP-A IASI observations}

In this paper, we will mainly show results obtained from the Joint Airborne IASI Validation Experiment (JAIVEx). JAIVEx was conducted from 14 April to 4 May 2007 to under-fly and gather validation datasets for the IASI observations. Flights were made over the Gulf of Mexico and over the US Department of Energy Oklahoma ARM-CART (Atmospheric Radiation Measurement - Cloud And Radiation Test-bed) site. Radiosondes and dropsondes were launched from the ARM-CART site and from the BAE-146 aircraft during Metop-A overpasses.

Figure 12 shows a flow diagram of how we perform super channel retrievals using IASI data. The algorithm starts by reading in forward model parameter files, cloud property
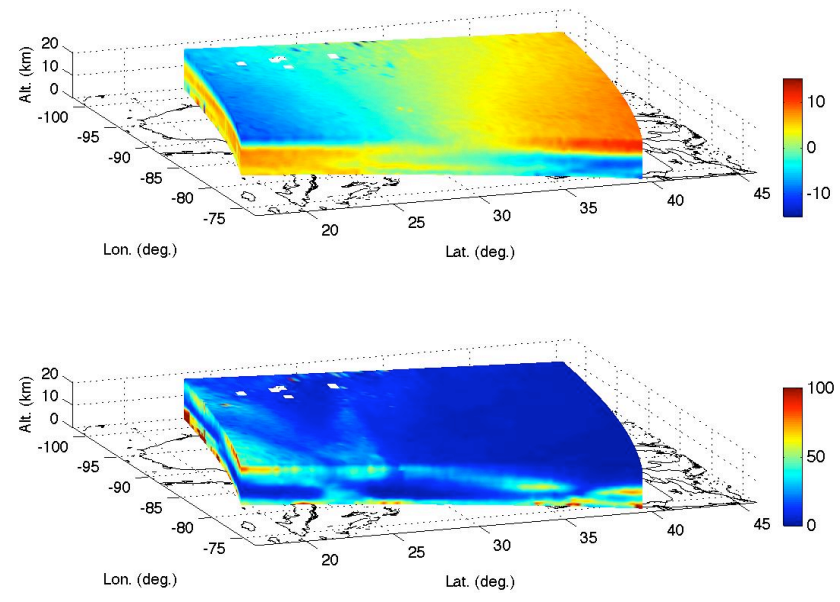

Fig. 14. Cross sections of the temperature and relative humidity retrieved from IASI spectra taken on 29 April 2007.

files, climatology covariance matrix and associated background vector, and the sensor information such as instrument noise. The IASI super channels are generated by projecting the observed IASI spectrum onto eigenvectors shown in Fig. 1. The PCRTM forward model is used to convert state vector into calculated super channels. Equation (8) is followed to update the state vector and fit the IASI super channels. The iterative retrieval continues until one of the exit criteria is reached.

\subsection{Retrieved three-dimensional atmospheric structures}

The plots in Fig. 13 show the cross sections of the atmospheric temperature and relative humidity retrieved from IASI spectra taken on 19 April 2007 using the PCRTM retrieval algorithm. The altitude range shown in the figure is between 5 and $6 \mathrm{~km}$. The color variation represents the deviation of the temperature from the mean or the relative humidity. The white gaps are due to complex cloud scenes where the algorithm failed to converge. Due to the high information content of the IASI spectra and the ability to use all IASI channels, fine details of atmospheric structure are well captured. These fine spatial details appear to be very coherent even though the retrieval was done on individual IASI Field Of Views (FOVs) without taking into consideration correlations between adjacent FOVs. It is clear that the moisture field has much finer spatial variations as compared to the temperature field, indicating that moisture is a good tracer for atmospheric motions. The detailed circulation patterns of the moisture field should provide useful information for weather prediction models to forecast cloud formations.

In contrast to the cross sections retrieved from 19 April 2007, the horizontal atmospheric structures are more uniform for 29 April 2007. Figure 14 shows the atmospheric temperature deviation from the mean and the relative humidity in 

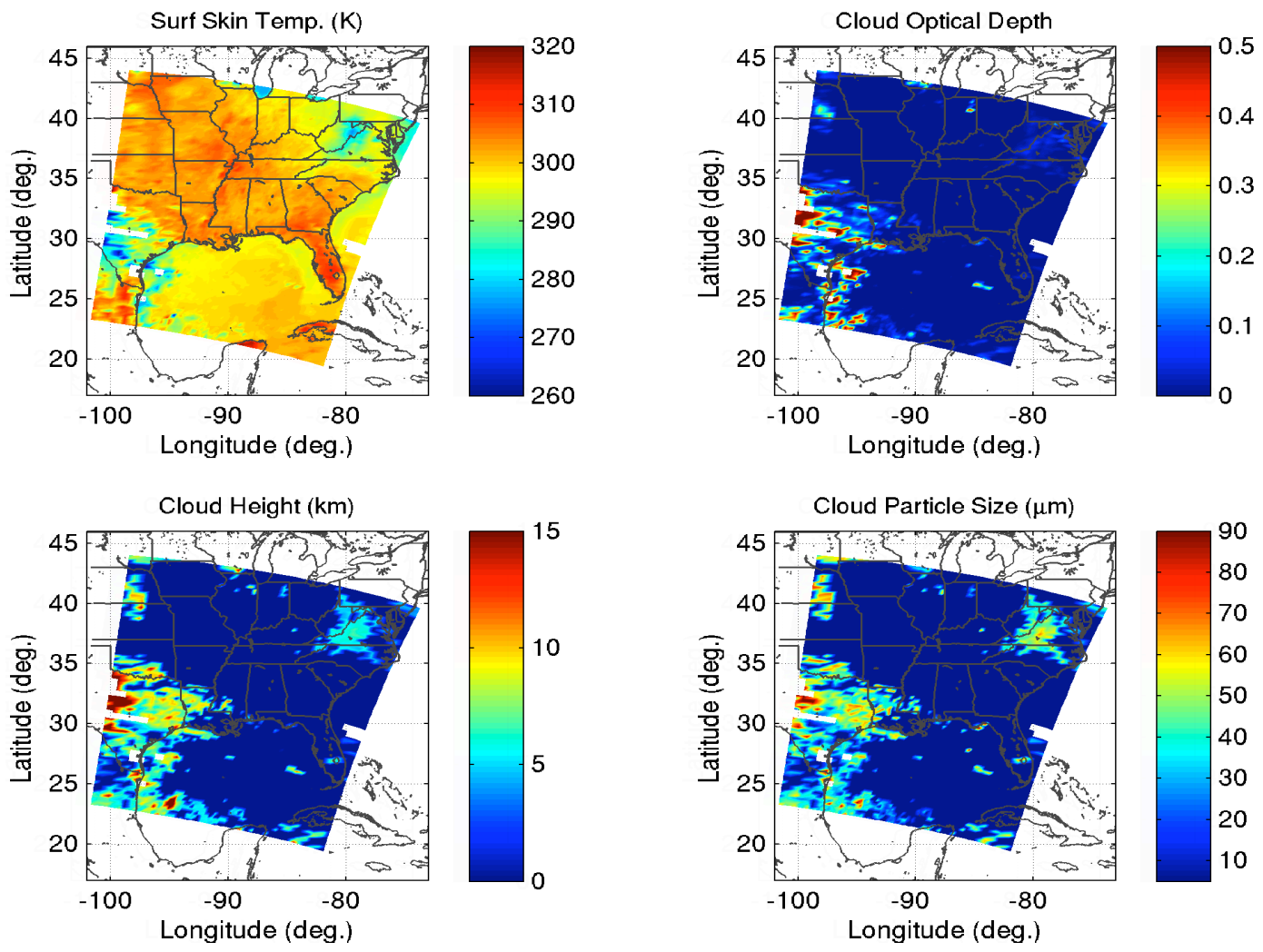

Fig. 15. Surface skin temperature; cloud optical depth, cloud height, and cloud particle size retrieved from IASI spectra taken on 29 April 2007.

the altitude range from surface to $18 \mathrm{~km}$. Again, the color variation represents the deviation of the temperature from the mean or the relative humidity. There is a lot of information on the retrieved three-dimensional atmospheric structures. For example, the upper atmosphere is warm and dry in the northwest side of the image, while the lower troposphere is cold with two moist layers moving horizontally.

\subsection{Cloud and surface properties}

The plots in Fig. 15 show retrieved surface skin temperature, cloud optical depth, cloud height, and cloud particle size from IASI spectra taken on 29 April 2007. The color scales are displayed in the figure. The white areas in the figure indicate the retrieval algorithm fails to converge due to multi-layer clouds or strong sun glint. Figure 16 shows the brightness temperature image of the IASI-integrated Imaging System (IIS). The IIS is an instrument that makes IR radiance measurements in the spectral range from 10.3 to $12.5 \mu \mathrm{m}$. In contrast to the IASI sounder which has 2 by 2 fields of view within a cell size of $45 \mathrm{~km}$, the IIS has 64 by 64 pixels within the same cell size. Because of the high spatial resolution, the IASI imager brightness temperature provides good information on cloud occurrences. Overall, the retrieved cloud field from the IASI sounder compares well with the observa-

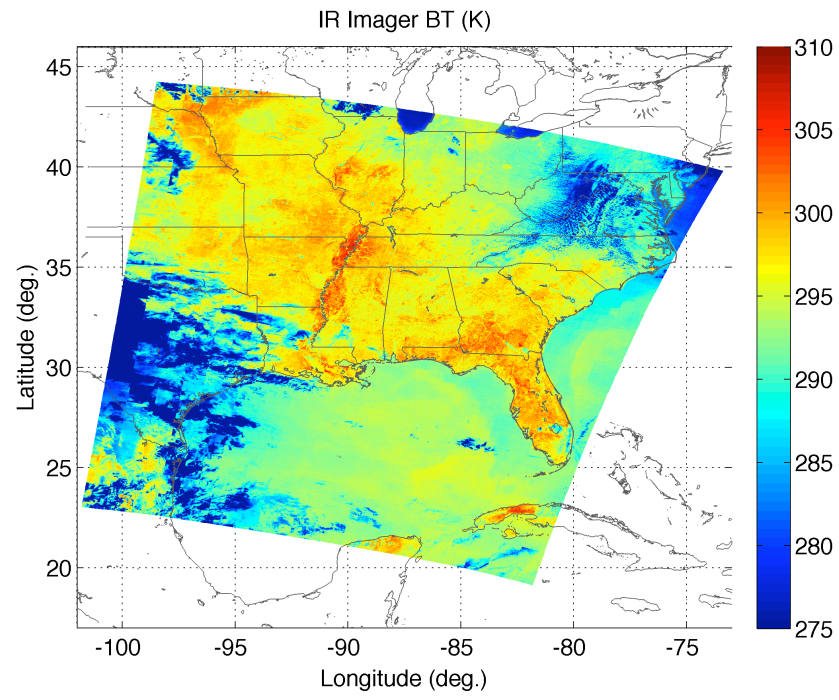

Fig. 16. Brightness temperature measured by the high spatial resolution IASI imager taken on 29 April 2007.

tions from a collocated the IIS. For example, the altocumulus clouds near West Virginia (near $38^{\circ}$ latitude, $-79^{\circ}$ longitude) as seen by the imager are well captured by the physical 


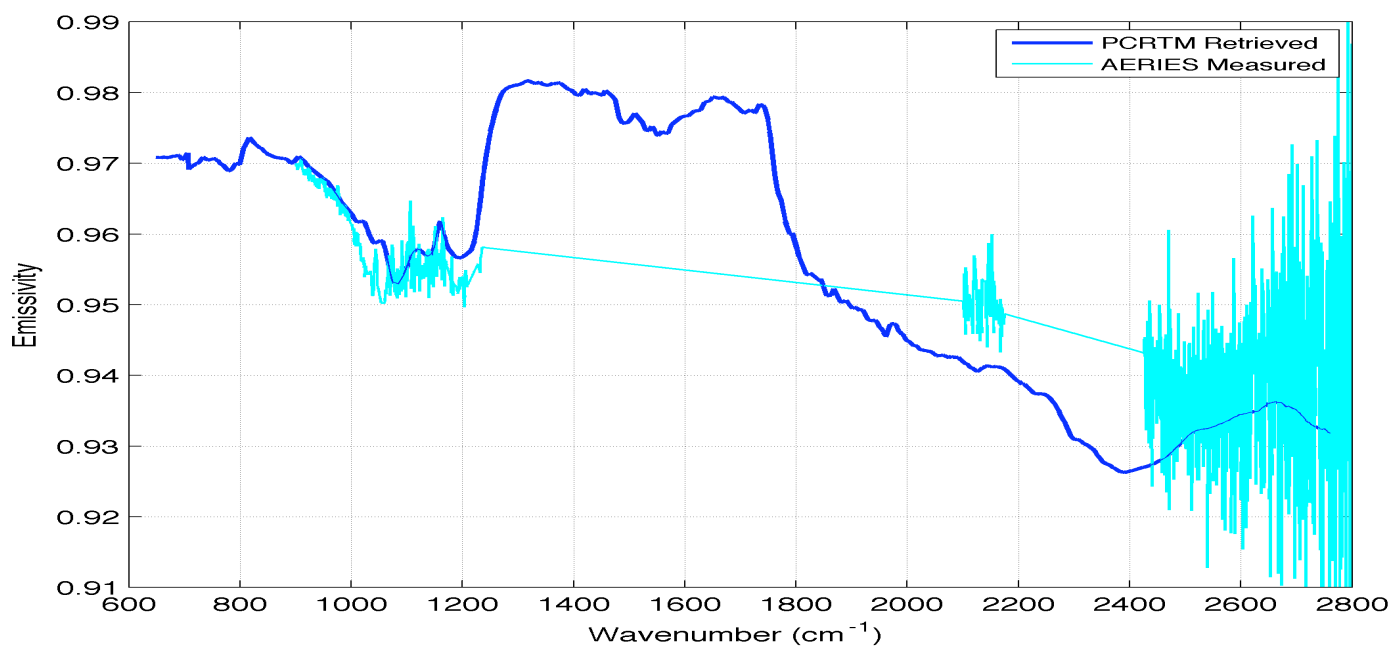

Fig. 17. Blue line: Surface emissivity retrieved from IASI spectra and taken on 19 April 2007. Cyan line: land surface emissivity over DOE-CART ARM site derived from the low flying ARIES instrument.

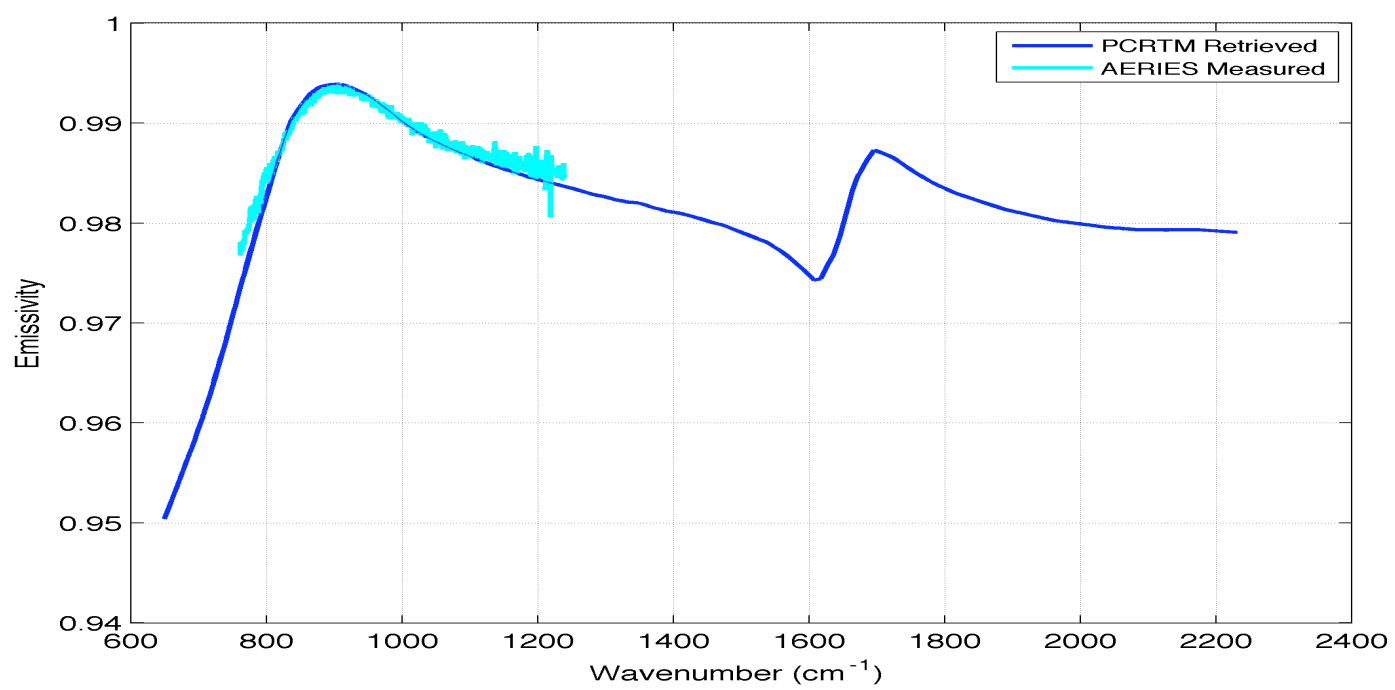

Fig. 18. Blue line: Surface emissivity retrieved from IASI spectra over the Gulf of Mexico on 30 April 2007. Cyan line: surface emissivity derived from the low flying ARIES instrument.

retrieval algorithm. The retrieved cloud height is around $5 \mathrm{~km}$ with visible optical depth around 0.15 . The cloud optical depth is effective because the clouds in this region may not cover the whole IASI FOVs, The surface skin temperatures under those altocumulus clouds are in the range of 284$288 \mathrm{~K}$, which is colder than the surrounding areas. This observation is consistent with the surface level air temperatures from radiosonde measurements in that area. The IASI measurements should see the surface in these area based on the imager data and on the retrieved small cloud optical depths. The cloud features near the Nebraska and Kansas state line (near $40^{\circ} \mathrm{N}$ latitude, $97^{\circ} \mathrm{W}$ longitude) seem to be high cirrus clouds $(5-13 \mathrm{~km})$ with a retrieved visible optical depths ranging from 0.1 to 0.2 . The retrieved skin temperatures are similar to those of surrounding areas, again indicating that the physical retrieval system is capable of retrieving accurate surface properties in the presence of thin cirrus clouds. As mentioned in Sect. 2.2, we have not performed any cloud retrieval validation due to the lack of quantitative truth data. The primary focus herein is on clear-air retrievals, and cloud parameter retrievals are included to show corresponding applicability of PCRTM methodology.

Table 2 tabulates a quantitative comparison of the retrieved surface skin temperature from the IASI spectra with those measured by the UK Met Office's Airborne Research Interferometer Evaluation System (ARIES) instrument for 19 April, 29 April, 30 April, and 4 May 2007. ARIES is an FTIR thermal emission radiometer with a $1 \mathrm{~cm}^{-1}$ 
Table 2. Comparison of the PCRTM retrieved surface skin temperature from the IASI spectra with those measured by the ARIES instrument for 19 April, 29 April, 30 April, and 4 May 2007.

\begin{tabular}{ccccccc}
\hline Date & Location & $\begin{array}{c}\text { Surface pressure } \\
(\mathrm{hPa})\end{array}$ & $\begin{array}{c}\text { Latitude/longitude } \\
\text { (degree) }\end{array}$ & $\begin{array}{c}\text { Satellite overpass } \\
\text { time (UTC) }\end{array}$ & $\begin{array}{c}\text { Skin temperature } \\
\text { from ARIES (K) }\end{array}$ & $\begin{array}{c}\text { Skin temperature } \\
\text { from IASI (K) }\end{array}$ \\
\hline 19 Apr 2007 & Land & 972.0 & $88.5^{\circ} \mathrm{W} / 26.5^{\circ} \mathrm{N}$ & $03: 35$ & 284.7 & 284.8 \\
29 Apr 2007 & Ocean & 1021.7 & $90.5^{\circ} \mathrm{W} / 26.9^{\circ} \mathrm{N}$ & $15: 50$ & 297.8 & 297.6 \\
30 Apr 2007 & Ocean & 1017.5 & $88.5^{\circ} \mathrm{W} / 26.5^{\circ} \mathrm{N}$ & $15: 29$ & 298.6 & 298.1 \\
4 May 2007 & Ocean & 1009.9 & $92.0^{\circ} \mathrm{W} / 27.5^{\circ} \mathrm{N}$ & $15: 46$ & 297.4 & 297.1 \\
\hline
\end{tabular}

wavenumber maximum spectral resolution over the range 600 to $3000 \mathrm{~cm}^{-1}$ wavenumbers. The method for deriving surface skin temperatures from the ARIES instrument is described by Newman et al. (2005). The agreement between the PCRTM retrieved and the ARIES measured skin temperatures is better than $0.5 \mathrm{~K}$ with a mean difference of $0.18 \mathrm{~K}$. It should be noted that the footprint sizes of IASI and ARIES are different in the cross-track direction because the ARIES only makes NADIR measurements.

Figures 17 and 18 are plots of PCRTM retrieved surface emissivity spectra and those measured by the ARIES instrument for 19 April and 30 April. The ARIES instrument did not measure surface emissivity on 29 April and 4 May. For the purpose of measuring surface emissivity and surface skin temperature, the ARIES instrument flew close to the Earth's surface at very low altitudes. The ARIES instrument measured both upwelling and downwelling radiation and these radiances are then used to retrieve the surface emissivity and skin temperature simultaneously. There are many spectral regions where the ARIES does not provide surface emissivity retrievals because of the interferences from atmospheric $\mathrm{CO}_{2}, \mathrm{H}_{2} \mathrm{O}$, and solar radiation. For the case of 19 April over the ARM-CART site, the IASI-retrieved emissivity agrees with the ARIES measured emissivity within 0.01 units. This agreement is good considering that the emissivity over the ARM-CART site is highly dependent on the percent coverage of vegetation within a specific area. The IASI covers a ground footprint of $12 \mathrm{~km}$ at nadir, while the ARIES instrument only covers tens of meters when flying near the surface. To minimize the difference due to spatial coverage, ARIES emissivity data is spatially averaged along the flight track during the IASI satellite overpass time. For 30 April 2007, the validation is during daytime and the IASI overpass took place over ocean in Gulf of Mexico. There is no ARIES emissivity retrieval at short wavelengths due to solar contaminations. The agreement between the ARIES measured and the IASI-retrieved emissivity is much better (within 0.003) because the ocean surface is more uniform relative to land.

\subsection{Atmospheric temperature and moisture profiles}

Section 4.1 has shown that the IASI instrument is capable of providing very detailed atmospheric temperature and moisture structures by using the PCRTM retrieval approach. In this section, we will perform case studies for 19 April, 29 April, 30 April, and 4 May 2007 during the JAIVEx campaign. The four cases were chosen based on coincidence of the aircraft under flights and the drop sondes with the IASI footprints. The location, the surface conditions and the time of satellite overpasses are listed in Table 2. At this stage of analysis, only clear FOVs are chosen for quantitative comparisons. Because the ARIES instrument only has NADIR views, the IASI scan angles are all close to NADIR views as well. We will show comparisons of the IASI-retrieved temperature and moisture profiles with those measured by the collocated dropsondes and the ECMWF model. We will analyze the retrieval quality by looking at the associated averaging kernels and the retrieval error covariance matrix.

Figure 19 shows comparisons of the retrieved temperature and moisture vertical profiles with collocated dropsondes over the Oklahoma ARM CART site on 19 April 2007. The METOP-A satellite over-passed the ARM site around 03:35 UTC. Dropsondes were launched by the FAAM BAE146 aircraft, which flew a north-south track in the vicinity of the ARM-CART site near Lamont. Because the BAE-146 aircraft flew at an altitude of $12 \mathrm{~km}$, ECMWF temperature and moisture profiles were used and interpolated to the location of the dropsondes for altitudes above the aircraft flying level. From the METOP-A AVHRR images, there were no clouds above at all levels during the time of the satellite overpass at 03:35 UTC. The climatology background was used for the first guess in the retrieval and they are plotted as black lines in Fig. 19. The IASI FOVs were selected based on the closeness to the BAE-146 flight path. The differences between the dropsonde and the retrieval are shown in the plots that are located in the second column of the figure. The averaging kernels and their integrated area for temperature and moisture profiles are shown in plots located on the right side of the first and second rows. The relative humidity and difference plots are also shown on the left side of the bottom row. The temperature and moisture error estimates 

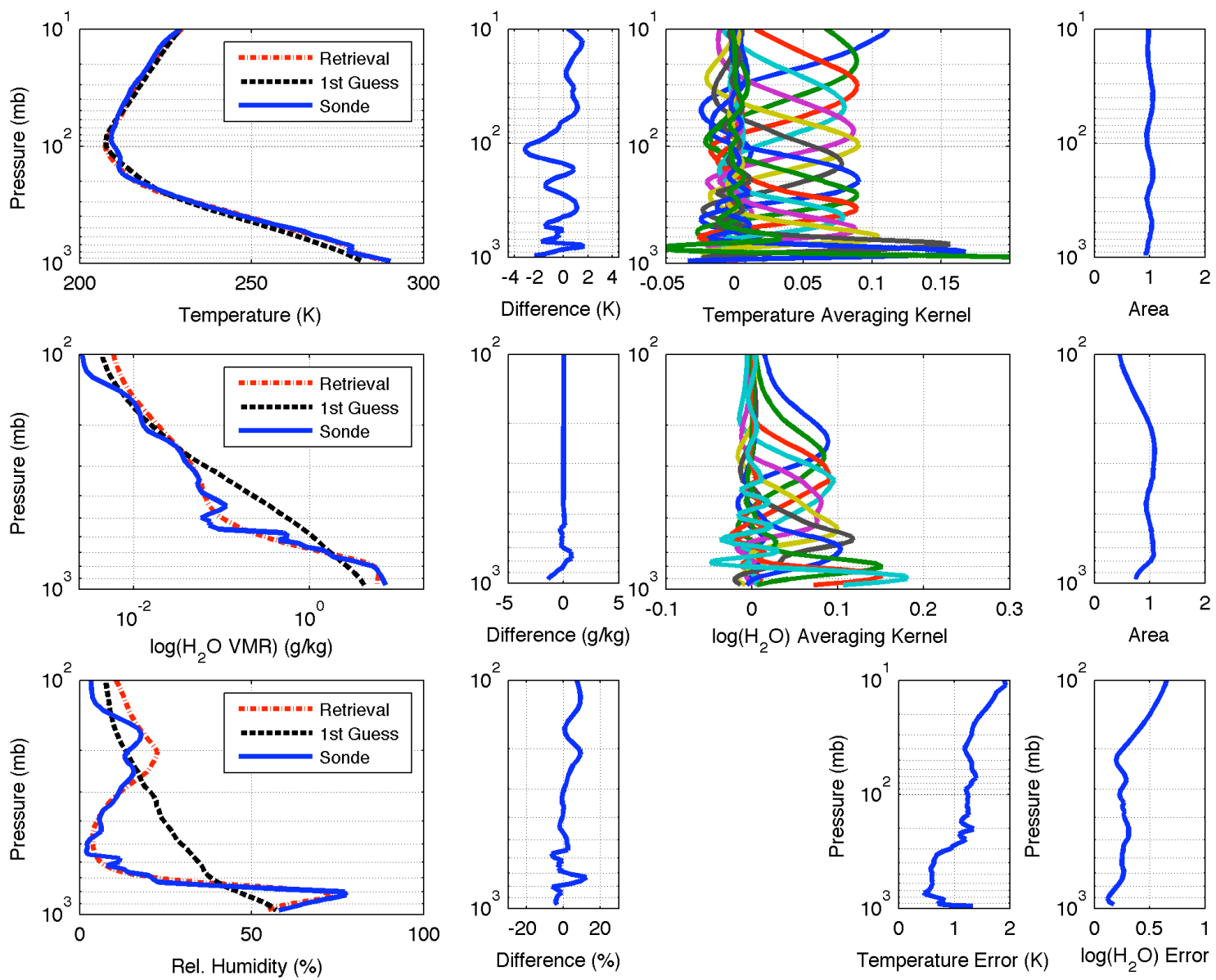

Fig. 19. Top left panels: Temperature profiles of the dropsonde from the BAE-140 aircraft and the ECMWF model (blue line), the climatology first guess (black line), and the PCRTM retrieval (red line) for 19 April 2007. The difference plot is between the dropsonde and the retrieval. Top right panels: Temperature averaging kernels and the integrated area. Middle left panels: Moisture profiles of the dropsonde, the climatology first guess, and the PCRTM retrieval. The difference plot is between the radiosonde and the retrieval in mixing ratio unit. Middle right panels: Moisture averaging kernels in logarithm unit and the integrated area. Bottom left panels: Relative humidity profiles of the dropsonde, the climatology first guess, and the PCRTM retrieval. The difference plot is between the radiosonde and the retrieval. Bottom right panels: The temperature and moisture error estimates from the retrieval covariance matrix (Eq. 11).

from the retrieval covariance matrix are plotted on the bottom right portion of the figure. The agreement between the IASI-retrieved and the dropsonde/ECMWF temperature profiles are very good except near $90 \mathrm{hPa}$. The fine-scale error pattern is due to the null-space error which the retrieval system has no sensitivity. Typically, these fine-scale error features are smaller than the half width of the corresponding averaging kernel. It is evident from Fig. 19 that the integrated area for the temperature averaging kernels are all close to 1.0, indicating that the IASI measurement contains 100 percent information relative to climatology background. In order to resolve those fine vertical structures, other a priori information such as NWP forecast error covariance matrix and the associated forecast temperature profiles are needed. Because the water vapor mixing ratio changes by two orders of magnitude from surface to tropopause, the moisture profiles are plotted in logarithmic scale. The averaging kernels and the retrieval error estimates are also related to the logarithm of water mixing ratio. The difference plot between the dropsonde and the retrieval is presented as mixing ratio in $\mathrm{g} / \mathrm{kg}$ since we cannot take a logarithm of the negative numbers. It is therefore difficult to see the retrieval error in the difference plot. In general, as the altitude increases the retrieval error gets larger and the averaging kernel gets broader. As mentioned before, the integrated areas of averaging kernels for pressure levels less than $200 \mathrm{hPa}$ are smaller than one, indicating that the climatology background contribute to the final solution. The retrieval errors are largest above $200 \mathrm{hPa}$ which is consistent with the retrieval error estimate and the averaging kernel area. For levels between the surface $(972 \mathrm{hPa})$ and $800 \mathrm{hPa}$, the retrieved moisture profile also depends on the shape of the first guess. Fortunately for this day, the moisture 

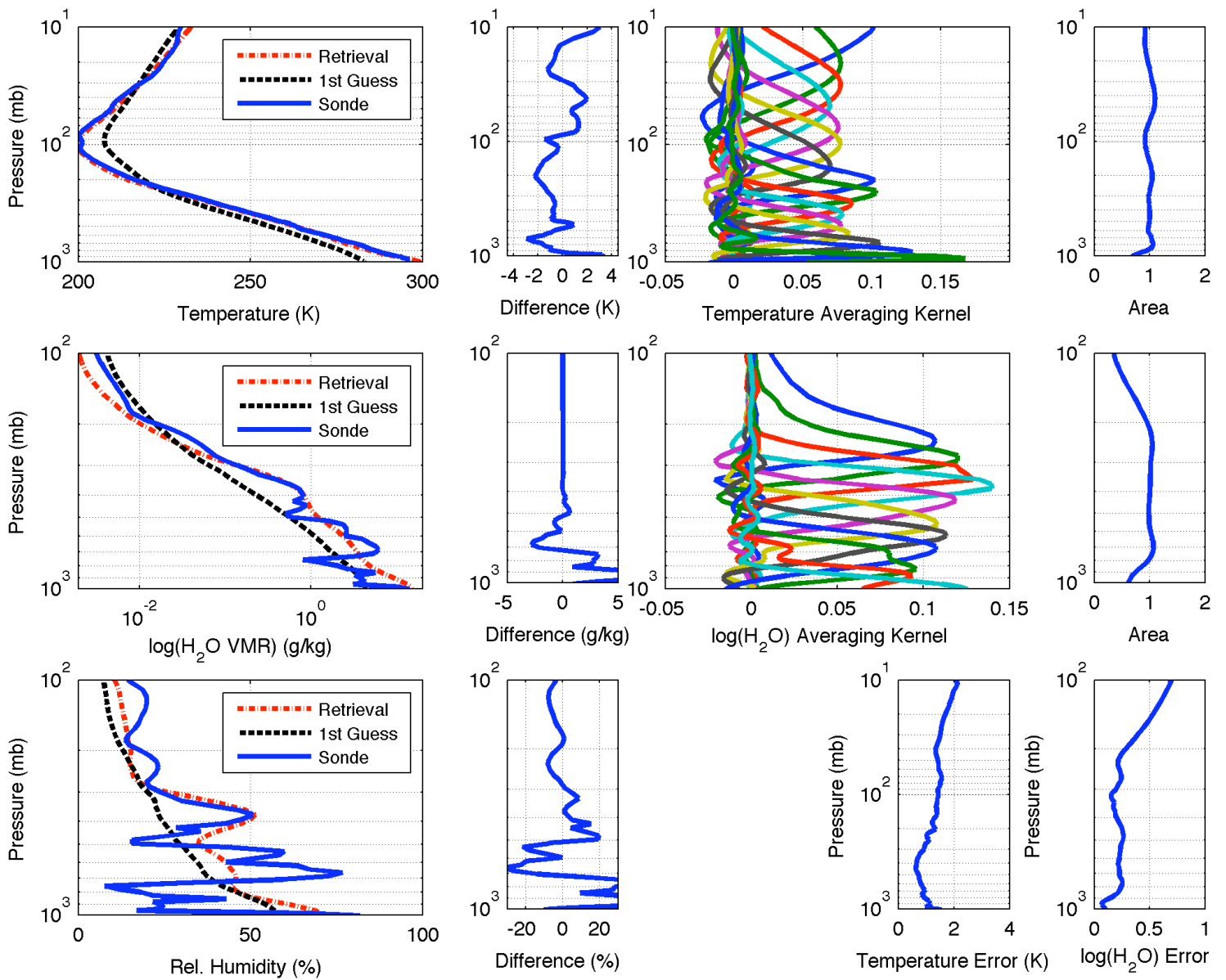

Fig. 20. Same as Fig. 19, except for 29 April 2007 over the Gulf of Mexico.

structure below 800 mbar is smooth and has similar shape as the a priori moisture profile. The retrieval performance is good for this case. The relative humidity plot shows more clearly how the retrieval is able to capture the large structure of the moisture vertical profile. For this case the relative humidity errors are less than 15 percent between the surface and $100 \mathrm{hPa}$. The agreement between the IASI-retrieved and the dropsonde/ECMWF temperature profiles are very good except near $90 \mathrm{hPa}$. The fine-scale error pattern is due to the null-space error which the retrieval system has no sensitivity. Typically, these fine-scale error features are smaller than the half width of the corresponding averaging kernel. It is evident from Fig. 19 that the integrated area for the temperature averaging kernels are all close to 1.0, indicating that the IASI measurement contains 100 percent information relative to climatology background. In order to resolve those fine vertical structures, other a priori information such as NWP forecast error covariance matrix and the associated forecast temperature profiles are needed. Because the water mixing ratio changes by two orders of magnitude from surface to tropopause, the moisture profiles are plotted in logarithmic scale. The averaging kernels and the retrieval error estimates are also related to the logarithm of water mixing ratio. The difference plot between the dropsonde and the retrieval is presented as mixing ratio in $\mathrm{g} / \mathrm{kg}$ since we cannot take a logarithm of the negative numbers. It is therefore difficult to see the retrieval error in the difference plot. In general, as the altitude increases the retrieval error gets larger and the averaging kernel gets broader. As mentioned before, the integrated areas of averaging kernels for pressure levels less than $200 \mathrm{hPa}$ are smaller than one, indicating that the climatology background contributes to the final solution. The retrieval errors are largest above $200 \mathrm{hPa}$ which is consistent with the retrieval error estimate and the averaging kernel area. For levels between the surface $(972 \mathrm{hPa})$ and $800 \mathrm{hPa}$, the retrieved moisture profile also depends on the shape of the first guess. Fortunately for this case, the moisture structure below 800 mbar is smooth and has similar shape as the a priori moisture profile. The retrieval performance is good for this case. The relative humidity plot shows more clearly how the retrieval is able to capture the large structure of the moisture vertical profile. For this case the relative humidity errors are less than 15 percent between the surface and $100 \mathrm{hPa}$. 

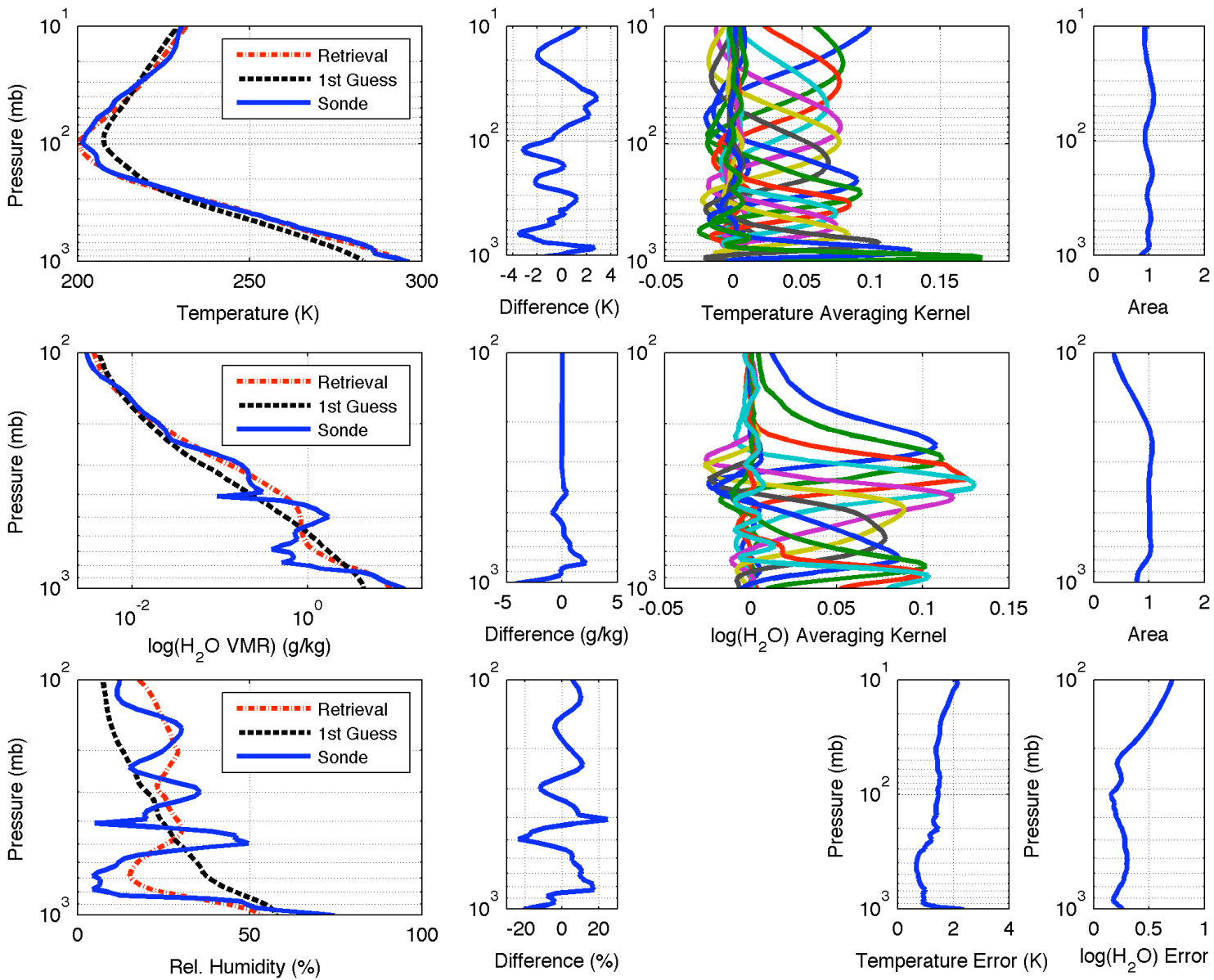

Fig. 21. Same as Fig. 19, except for 30 April 2007 over the Gulf of Mexico.

Figure 20 is the case study for 29 April 2007. The aircraft flew a track running along the $90.5^{\circ} \mathrm{W}$ meridian over the ocean in the Gulf of Mexico. The IASI overpass time is at 15:50 UTC. For the region near $90.5^{\circ} \mathrm{W}$ and $26.9^{\circ} \mathrm{N}$, the sky is free of clouds as identified in METOP AVHRR images. Our retrievals also show that the cloud optical depth is zero in this region (see Fig. 15). It can be seen that the temperature difference between the IASI retrieved and the dropsonde is large near the surface. The temperature averaging kernel for altitude below $900 \mathrm{hPa}$ is about 0.7 , indicating that the IASI spectrum does not provide 100 percent of the temperature information in this altitude range. This disparity is caused by the very small thermal contrast between the near surface air and the ocean surface. The dropsonde shows that the near surface air temperature is $296.64 \mathrm{~K}$ while the ocean surface temperature is $297.8 \mathrm{~K}$. In addition to the low surface to air thermal contrast, the dropsonde measurement shows that the air temperature between $950 \mathrm{hPa}$ to $1022 \mathrm{hPa}$ is almost isothermal. Due to the small thermal contrast, any emissions and absorptions by the atmospheric $\mathrm{CO}_{2}$ and $\mathrm{H}_{2} \mathrm{O}$ below 950 mbar will have very small signals, making it difficult to retrieve both temperature and moisture profile in this narrow pressure range. The a priori profile (black line on the top right panel in Fig. 20) does not help the retrieval to get the isothermal structure since the background air temperature monotonically changes with pressure near the surface. For the case of 19 April, the near surface air temperature is about $4 \mathrm{~K}$ higher than the surface skin temperature and the air temperature increases with altitude; therefore the temperature averaging kernel near the surface is close to 1.0. Errors for the retrieved moisture profile for 29 April are larger than that of 19 April. The dropsonde moisture profile shows very fine vertical structures which are smaller than the half width of the moisture averaging kernels. The retrieval does capture the general shape of the moisture variation with the altitude. The errors are larger for pressure levels less than $200 \mathrm{mbar}$ and for those levels between $800 \mathrm{mbar}$ and the surface. This result is consistent with the averaging kernel information. For the altitude range between 500 mbar and 800 mbar, the errors seem to be larger than what is expected from the averaging kernels. This result may be due to too strong of regularization applied to the non-linear inversion process and will be studied further in the future. 

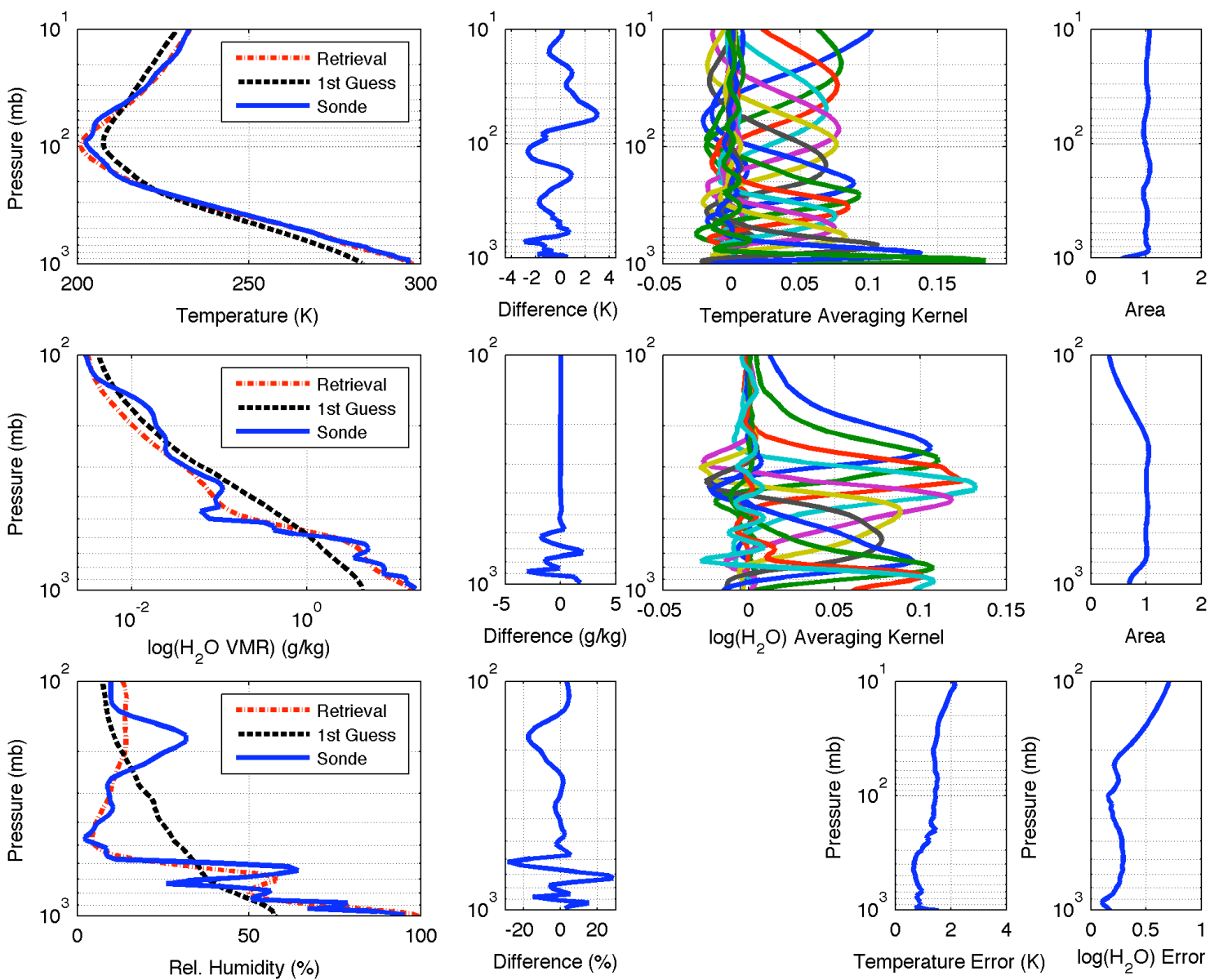

Fig. 22. Same as Fig. 19, except for 4 May 2007 over the Gulf of Mexico.

Figure 21 is the case study for 30 April 2007. The IASI overpass time is at 15:29 UTC. The coincident measurements were made in a region near $88.5^{\circ} \mathrm{W}$ and $26.5^{\circ} \mathrm{N}$ over the ocean in the Gulf of Mexico. Figure 22 is the case study for 4 May 2007. The IASI overpass time is at 15:46 UTC. The coincident measurements were made in a region near $92^{\circ} \mathrm{W}$ and $27.5^{\circ} \mathrm{N}$ over the Gulf of Mexico as well. The retrieval performance is very similar to that of 29 April 2007. The temperature integrated areas of the averaging kernel for altitude below $900 \mathrm{hPa}$ are smaller than 1.0. For both of these days, the thermal contrast between ocean surface and the near surface air temperature is still small (less than $1 \mathrm{~K}$ ). The retrieved moisture profiles have captured the broad features while they missed all the fine details. For the cases of 29 April, 30 April, and 4 May, the measurements were made during the day-time and the retrievals do not use spectral region greater than $2000 \mathrm{~cm}^{-1}$ because handling solar radiation is not yet included in the retrieval process. When the solar zenith angle is less than 89 degrees, the magnitude of the solar component in spectral region $1800-2000 \mathrm{~cm}^{-1}$ typically varies from $0.1 \mathrm{~K}$ to $5 \mathrm{~K}$ in brightness temperature units, depending on the atmospheric conditions. We account for this error source by adding an equivalent of $10 \mathrm{~K}$ error (brightness temperature calculated at $280 \mathrm{~K}$ ) in this spectral region when we generate the $S_{y}$ error covariance matrix during the inversion process. We will include the solar modeling and other trace gases in our future studies.

\section{Summary and conclusions}

We have demonstrated that by converting IASI spectra into super channels, we can retrieve atmospheric and surface properties efficiently from a PCRTM-based inversion algorithm. By performing the retrieval in EOF space, the algorithm is essentially using all the available IASI spectral information, but with a much smaller dimensions and faster speed. For a given state vector, the PCRTM model provides PC scores and associated Jacobian. The inversion approach is based on a maximum-likelihood method and uses the Levenberg-Marguardt algorithm for dealing with nonlinearity of the radiative transfer equation. We plan to run the PCRTM model in both the PC and the channel spaces so that we can quantify the pros and cons of the PC-based 
methodology. In addition to atmospheric temperature and moisture profiles, cloud properties such as cloud optical depth, cloud particle size, cloud phase, and cloud top pressure are retrieved directly. Unlike the cloud-clearing algorithm, which relies on several FOVs in order to generate cloud-cleared radiances, the PCRTM-based retrieval algorithm is performed on a single IASI field of view (FOV) and can be done for both clear and cloudy FOVs. Currently, we have no quantitative validation of the retrieved cloud parameters and we plan to validate our cloud retrieval methodology by collocating IASI data with those from A-train data in a future study.

We have applied the super channel retrieval algorithm to IASI spectra taken during the JAIVEx field campaign in the spring of 2007. The retrieval algorithm is capable of fitting IASI radiances to within instrument noise level at most frequency ranges. Currently, we set the "noise-level" as the original IASI instrument noise specifications. Although the radiance residuals in many spectral regions (most noticeably in band 3) are much less than the native IASI noise, we decided not to fit the radiance spectrum to the PC-filtered noise level at this stage because we have not accounted for many error sources such as uncertainty in spectroscopy and errors caused by trace gases that are not currently retrieved in the inversion process. Due to the high information content of the IASI instrument, three-dimensional atmospheric structure can be effectively retrieved using the PCRTM-based retrieval algorithm. The retrieved cloud features compare well with the collocated IIS data. The retrieved surface emissivity data and surface skin temperatures compare well with the measurements from the ARIES instrument. Quantitative comparisons of the retrieved atmospheric temperature and moisture profiles have been compared with airborne dropsonde measurements from the BAE-146 aircraft for 19 April, 29 April, 30 April, and 4 May. Averaging kernels corresponding to those retrievals have been plotted to reveal the insight of the vertical resolution of the retrieved temperature and moisture profiles. The integrated areas and the peak locations of the averaging kernels provide the information content for each atmospheric level. In general, the retrieval errors are consistent with the information content analysis and the error estimate from the retrieval system. Although, ozone and $\mathrm{CO}$ are already retrieved in our current algorithm, we will validate the products in our future work. We plan to further study the impact of a priori information and the effect of not retrieving other trace gases on accuracy of temperature and moisture retrievals.

Acknowledgements. The authors would like to thank for the contributions from the NASA Langley Research Center, the EUMETSAT, the UK Met Office, and the Space Science and Engineering Center of the University of Wisconsin-Madison. Thanks to NCAR team (especially L. Emmons) for MOZART CO and other trace gas profiles. This work is supported by funds from the NASA Headquarters and the NPOESS Integrated Program Office (IPO). The FAAM is jointly funded by the UK Met Office and the
Natural Environment Research Council. IASI has been developed and built under the responsibility of the Centre National d'Etudes Spatiales (CNES, France). It is flown onboard the Metop satellites as part of the EUMETSAT Polar System. The IASI L1 data are received through the EUMETCast near real time data distribution service. We thank Ping Yang and his group for providing the cloud properties used in this study. We would also like to thank the anonymous reviewers for their comments and suggestions.

Edited by: T. Wagner

\section{References}

Aoki, T.: Channel Compression of Trace Gas Remote Sounder by Expanding the Weighting Function with Empirical Orthogonal Functions, J. Meteorol. Soc. Jpn., 82, 1081-1093, 2004.

Aoki, T.: Channel Compression of High Resolution Infrared Spectra with Using Hypothetical Channel System, J. Meteorol. Soc. Jpn., 83, 41-55, 2005.

Aumann, H. H., Chahine, M. T., Gautier, C., Goldberg, M. D., Kalnay, E., McMillin, L. M., Revercomb, H., Rosenkranz, P. W., Smith, W. L., Staelin, D. H., Strow, L. L., and Sussind, J.: AIRS/AMSU/HSB on Aqua Mission: Design, Science objectives, data products, and processing system, IEEE Trans. Geosci. Rem. Sens., 41, 253-264, 2003.

Barnet, C. D., Blaisdell, J. M., and Susskind, J.: Practical Methods for Rapid and Accurate Computation of Interferometric Spectra for Remote Sensing Applications, IEEE Trans. Geosci. Rem. Sens., 38, 169-183, 2000.

Blumstein, D., Chalon, G., Carlier, T., Buil, C., Hebert, P., Maciaszek, T., Ponce, G., and Phulpin, T.: IASI instrument: technical overview and measured performances, SPIE Proc., 5543, 196-207, 2004.

Baum, B. A., Yang, P., Nasiri, S., Heidinger, A. K., Heymsfield, A. J., and Li, J.: Bulk Scattering Properties for the Remote Sensing of Ice Clouds. III: High resolution spectral models from 100 to $3250 \mathrm{~cm}^{-1}$, J. Appl. Meteor. Clim., 46, 423-434, 2007.

Chahine, M. T.: Remote sounding cloudy atmospheres. I. The Single Cloud Layer, J. Atmos. Sci., 31, 233-243, 1974.

Chahine, M. T.: Remote sounding cloudy atmospheres. II. Multiple Cloud Formations, J. Atmos. Sci., 34, 744-757, 1977.

Chahine, M. T., Aumann, H., Goldberg, M., McMillin, L., Rosenkranz, P., Staelin, D., Strow, L., Susskind, J., and Gunson, M.: AIRS Level 2 Algorithm Theoretical Basis Document Version 2.2, JPL D-17006, 2001.

Clough, S. A. and Iacono, M. J.: Line-by-line calculation of atmospheric fluxes and cooling rates: 2. Application to carbon dioxide, ozone, methane, nitrous oxide and the halocarbons, J. Geophys. Res., 100, 16579-16593, 1995.

Collard, A.: Selection of IASI Channels for Use in Numerical Weather Prediction, Q. J. Roy. Meteorol. Soc., 629, 1977-1991, 2007.

Collard, A. and McNally, T.: Operational Assimilation of IASI radiances at ECMWF, Joint Center for Satellite Data Assimilation Quarterly, 22, 2-3, 2008.

Crevoisier, C., Chedin, A., and Scott, N.: AIRS channel selection for $\mathrm{CO}_{2}$ and other trace-gas retrievals, Q. J. Roy. Meteorol. Soc., 129, 2719-2740, 2003. 
Edwards, D. P. and Francis, G. L.: Improvements to the correlated-k radiative transfer method: Application to satellite infrared sounding, J. Geophys. Res., 105(D14), 18135-18156, 2000.

Eyre, J. R.: Inversion of cloudy satellite sounding radiances by nonlinear optimal interpolation. I: Theory and simluation for TOVS, Q. J. Roy. Meteorol. Soc., 115, 1001-1026, 1989a.

Eyre, J. R.: Inversion of cloudy satellite sounding radiances by nonlinear optimal estimation. II: Application to TOVS data, Q. J. Roy. Meteorol. Soc., 115, 1027-1037, 1989b.

Fourrié, N. and Thépaut, J.-N.: Validation of the NESDIS near real time AIRS channel selection. ECMWF Tech. Memo. 390, European Center for Medium Range Weather Forecasts, Reading, UK, 2002.

Fourrié, N. and Thépaut, J.-N.: Evaluation of the AIRS near-realtime channel selection for application to numerical weather prediction, Q. J. Roy. Meteorol. Soc., 129, 2425-2439, 2003.

Goldberg, M. D., Qu, Y., McMillin, L. M., Wolf, W., Zhou, L., and Divakarla, M.: AIRS near real-time products and algorithms in support of operational numerical weather prediction, IEEE Trans. Geosci. Rem. Sens., 41, 379-389, 2003.

Huang, H.-L. and Antonelli, P.: Application of principal component analysis to high-resolution infrared measurement compression and retrieval, J. Appl. Meteorol., 40, 265-388, 2001.

Huang, H.-L., Yang, P., Wei, H., Baum, B. A., Hu, Y. X., Atonelli, P., et al.: Inference of ice cloud properties from high-spectral resolution infrared observations, IEEE Trans. Geosci. Rem. Sens., 42, 842-852, 2004.

Niu, J. G., Ping, Y., Huang, H.-L., Davies, J. E., Li, J., Baumc, B. A., and Hu, Y. X.: A fast infrared radiative transfer model for overlapping clouds, J. Quant. Spectros. Radiat. Transfer, 103, 447-459, 2007.

Klaes, K. D., Cohen, M., Buhler, Y., Schluessel, P., Munro, P., Luntama, J.-P., Von Engeln, A., Clerigh, E. O., Bonekamp, H., Ackernmann, J., and Schmetz, J.: An introduction to the EUMETSAT Polar System, B. Am. Meteorol. Soc., 88, 1085-1096, 2007.

Kinnison, D. E., Brasseur, G. P., Walters, S., Garcia, R. R., Marsh, D. R., and Sassi, F., Harvey, V. L., Randall, C. E., Emmons, L., Lamarque, J. F., Hess, P., Orlando, J. J., Tie, X. X., Randel, W., Pan, L. L., Gettelman, A., Granier, C., Diehl, T., Niemeier, U., and Simmons, A. J.: Sensitivity of chemical tracers to meteorological parameters in the MOZART-3 chemical transport model, J. Geophys. Res., 112, D20302, doi:10.1029/2006JD007879, 2007.

Le Marshall, J., Jung, J., Derber, J., Chahine, M., Treadon, R., Lord, S., Goldberg, M., Wolf, W., Liu, H. C., Joiner, J., Woollen, J., Todling, R., van Delst, P., and Tahara, Y.: Improving Global Analysis and Forecasting with AIRS, B. Am. Meteorol. Soc., 87, 747-750, 2006.

Le Marshall, J., Jung, J., Derber, J., Treadon, R., Lord, S., Goldberg, M., Wolf, W., Liu, H. C., Joiner, J., Woollen, J., and Todling, R.: AIRS hyperspectral data improves southern hemisphere forecasts, Aust. Meteor. Mag., 54, 57-60, 2005a.

Le Marshall, J., Jung, J., Derber, J., Treadon, R., Lord, S., Goldberg, M., Wolf, W., Liu, H. C., Joiner, J., Woollen, J., and Todling, R.: Impact of Atmospheric InfraRed Sounder Observations on Weather Forecasts, EOS, 86, 109, 115, 116, 15 March 2005b.

Li, J., Liu, C. Y., Huang, H.-L., Schmit, T. J., Menzel, W. P., and Gurka, J.: Optimal cloud-clearing for AIRS radiances using MODIS, IEEE Trans. Geosci. Rem. Sens., 43, 1266-1278,
2005.

Liu, X. W., Smith, L., Zhou, D. K., and Larar, A.: A principal component-based radiative transfer forward model (PCRTM) for hyperspectral instruments, Proc. SPIE Int. Soc. Opt. Eng., 5655, 96-105, 2005.

Liu, X., Zhou, D. K., Larar, A., Smith, W. L., and Mango, S. A.: Case Study a New Radiative Transfer Model and Retrieval Algorithm using EAQUATE Data, Q. J. Roy. Meteorol. Soc., 133, 243-256, 2007.

Liu, X., Moncet, J.-L., Zhou, D. K., and Smith, W. L.: A Fast and Accurate Forward Model for NAST-I Instrument, in: Fourier Transform Spectroscopy and Optical Remote Sensing of Atmosphere, 2003 Technical Digest Series OSA (Optical Society of America, Washington, D.C., 2003), p. 16, 2003.

Liu, X., Smith, W. L., Zhou, D. K., and Larar, A.: Principal Component-based Radiative Transfer Forward Model (PCRTM) For Hyperspectral Sensors, Theoretical Concept, Appl. Optics, 45, 201-209, 2006.

Marquardt, D.:: An Algorithm for Least-Squares Estimation of Nonlinear Parameters, SIAM J. Appl. Math., 11, 431-441, 1963.

Masuda, K., Takashima, T., and Takayama, Y.: Emissivity of pure and sea waters for the model sea surface in the infrared window regions, Rem. Sens. Environm., 24, 319-329, 1988.

Matricardi, M.: RTIASI-4, a new version of the ECMWF fast radiative transfer model for infrared atmospheric sounding interferometer, ECMWF Tech. Memo., 425, 63 pp., 2003.

Matricardi, M. and Saunders, R. W.: A fast radiative transfer model for simulation of IASI radiances, Appl. Optics, 38, 5679-5691, 1999.

McMillin, L. M., Goldberg, M. D., Ding, H., Susskind, J., and Barnet, C. D.: A forward calculation for interferometers: method and validation, Appl. Optics, 37, 3059-3068, 1997.

McMillin, L. M., Crone, L. J., and Kleespies, T. J.: Atmospheric transmittance of an absorbing gas, 5, Improvements to the OPTRAN approach, Appl. Optics, 34, 8396-8399, 1995.

McMillin, L. M.: Super Channels for AIRS Retrievals, AMS 13th Conference on Satellite Meteorology and Oceanography, 1923 September 2004, Norfolk, VA, http://ams.confex.com/ams/ pdfpapers/78955.pdf, 2004.

Menzel, W., Smith T., and Stewart, T. R.: Improved cloud motion vector and altitude assignment using VAS, J. Appl. Meteorol., 22, 377-384, 1983.

Moncet, J.-L., Liu, X., Helene, R., Snell, H., Zaccheo, S., Lynch, R., Eluszkiewicz, J., He, Y., Uymin, G., Lietzke, C., Hegarty, J., Boukabara, S., Lipton, A., and Pickle, J.: Algorithm Theoretical Basis Document (ATBD) for the Cross Track Infrared Sounder (CrIS) Environmental Data Records (EDR), V1.2.3, AER Document Released to ITT and Integrated Program Office, 2001.

Moncet, J. L. and Clough, S. A.: Accelerated monochromatic radiative transfer for scattering atmospheres: application of a new model tospectral radiance observations, J. Geophys. Res., 102, 853-866, 1997.

Newman, S. M., Smith, J. A., Glew, M. D., Rogers, S. M., and Taylor, J. P.: Temperature and salinity dependence of sea surface emissivity in the thermal infrared, Q. J. Roy. Meteorol. Soc., 131, 2539-2557, 2005

Pagano, T. S., Aumann, H. H., Hagan, D. E., and Overoye, K.: Prelaunch and in-flight radiometric calibration of the Atmospheric Infrared Sounder (AIRS), IEEE Trans. Geosci. Rem. 
Sens., 41, 265-273, 2003.

Press, W. H., Teukolsky, S. A., Vetterling, W. T., and Flannery, B. P.: Numerical Recipes (second edition), Cambridge Press, 1992.

Prunet, P., Thépaut, J.-N., and Cassé, V.: The information content of clear sky IASI radiances and their potential for numerical weather prediction, Q. J. Roy. Meteorol. Soc., 124, 211-241, 1998.

Rabier, F., Fourrié, N., Chafaï, D., and Prunet, P.: Channel selection methods for Infrared Atmospheric Sounding Interferometer radiances, Q. J. Roy. Meteorol. Soc., 128, 1011-1027, 2002.

Rodgers, C. D.: Inverse Methods for Atmospheric Sounding - Theory and Practice, World Scientific, Singapore, pp 238, 2002.

Rodgers, C. D.: Retrieval of atmospheric temperature and composition from remote measurements of thermal radiation, Rev. Geophys. Space Phys., 14, 609-624, 1976.

Salisbury, J. W. and D'Aria, D. M.: Emissivity of terrestrial material in the 8-14 $\mu \mathrm{m}$ atmospheric window, Rem. Sens. Environ., 42, 83-106, 1992.

Saunders, R., Matricardi, M., and Brunel, P.: An improved fast radiative transfer model for assimilation of satellite radiance observations, Q. J. Roy. Meteorol. Soc., 125, 1407-1425, 1999.

Saunders, R., Rayer, P., Brunel, P., von Engeln, A., Bormann, N., Strow, L., Hannon, S., Heilliette, S., Liu, X., Miskolczi, F., Han, Y., Masiello, G., Moncet, J.-L., Uymin, G., Sherlock, V., and Turner, D. S.: A comparison of radiative transfer models for simulating AIRS radiances, J. Geophys. Res., 112, D01S90, doi:10.1029/2006JD007088, 2007.

Schluessel, P.: Super-Channel Selection for IASI Retrievals, ITSC XIV Proceedings, Beijing, China, 25-31 May 2005, (http://cimss.ssec.wisc.edu/itwg/itsc/itsc14/proceedings/ 11_2_Schluessel.pdf), 2005.

Schluessel, P., Hultberg, T. H., Phillips, P. L., August, T., and Calbet, X.: The operational IASI Level 2 processor, Adv. Space Res., 36, 982-988, 2005.

Segelstein, D. J.: The complex refractive index of water, Master's thesis, University of Missouri-Kansas City, 1981.

Smith, W. L.: An improved method for calculating tropospheric temperature and moisture from satellite radiometer measurements, Mon. Weather Rev., 96, 387-396, 1968.

Smith, W. L., Huang, H. L., and Jenney, J. A.: An advanced sounder cloud contamination study, J. Appl. Meteor., 35, 1249-1255, 1996.

Smith, W. L.: An improved method for calculating tropospheric temperature and moisture from satellite radiometer measurements, Mon. Weather Rev., 96, 387-396, 1968.

Stamnes, K., Tsay, S.-C., Wiscombe, W., and Jayaweera, K.: Numerically stable algorithm for discrete-ordinate-method radiative transfer in multiple scattering and emitting media, Appl. Optics, 27, 2502-2509, 1988.
Strow, L. L., Hannon, S. E., De Souza-Machado, S., Motteler, H. E., and Tobin, D.: An overview of the AIRS radiative transfer model, IEEE Trans. Geosci. Rem. Sens., 41, 303-313, 2003.

Strow, L. L., Hannon, S. E., De-Souza Machado, S., Motteler, H. E., and Tobin, D. C.: Validation of the Atmospheric Infrared Sounder radiative transfer algorithm, J. Geophys. Res., 111, D09S06, doi:10.1029/2005JD006146, 2006.

Susskind, J., Barnet, C., Blaisdell, J., Iredell, L., Keita, F., Kouvaris, L., Molnar, G., and Chahine, M.: Accuracy of geophysical parameters derived from Atmospheric Infrared Sounder/Advanced Microwave Sounding Unit as a function of fractional cloud cover, J. Geophys. Res., 111, D09S17, doi:10.1029/2005JD006272, 2006.

Susskind, J., Barnet, C. D., and Blaisdell, J. M.: Retrieval of atmospheric and surface parameters from AIRS/AMSU/HSB data in presence of clouds, IEEE Trans. Geosci. Rem. Sens., 41, 390409, 2003.

Warren, S. G.: Optical constants of ice from the ultraviolet to the microwave, Appl. Optics, 23, 1206-1225, 1984.

Wei, H., Yang, P., Li, J., Baum, B. A., Huang, H., Platnick, S., et al.: Retrieval of semitransparent ice cloud optical thickness from atmospheric infrared sounder (AIRS) measurements, IEEE Trans. Geosci. Rem. Sens., 42, 2254-2267, 2007.

Wu, X. Q. and Smith, W. L.: Emissivity of rough sea surface for 8-13 microns: Modeling and verification, Appl. Optics, 36(12), 2609-2619, 1997.

Yang, P., Gao, B. C., Baum, B. A., Hu, Y., Wiscombe, W. J., Tsay, S.-C., Winker, D. M., and Nasiri, S. L.: Radiative Properties of cirrus clouds in the infrared $(8-13 \mu \mathrm{m})$ spectral region, J. Quant. Spectros. Radiat. Transfer, 70, 473-504, 2001.

Zhang, Z., Yang, P., Kattawar, G., Huang, H.-L., Greenwald, T., Li, J., Baum, B. A., Zhou, D. K., and Hu, Y.: A fast infrared radiative transfer model based on the adding-doubling method for hyperspectral remote-sensing applications, J. Quant. Spectros. Radiat. Transfer, 105, 243-263, doi:10.1016/j.jqrt.2007.01.009, 2007.

Zhou, D. K., Smith Sr., W. L., Liu, X., Larar, A. M., Mango, S. A., and Huang, H.-L.: Physically retrieving cloud and thermodynamic parameters from ultraspectral IR measurements, J. Atmos. Sci., 64, 969-982, 2007.

Zhou, D. K., Smith, W. L., Liu, X., Larar, A. M., Huang, H.-L. A., Li, J., McGill, M. J., and Mango, S. A.: Thermodynamic and cloud parameters retrieval using infrared spectral data, Geophys. Res. Lett., 32, L15805, doi:10.1029/2005GL023211, 2005.

Zhou, D. K., Smith, W. L., Larar, A. M., Liu, X., Taylor, J. P., Schlüssel, P., Strow, L. L., and Mango, S. A.: All weather IASI single field-of-view retrievals: case study - validation with JAIVEx data, Atmos. Chem. Phys., 9, 2241-2255, 2009, http://www.atmos-chem-phys.net/9/2241/2009/. 